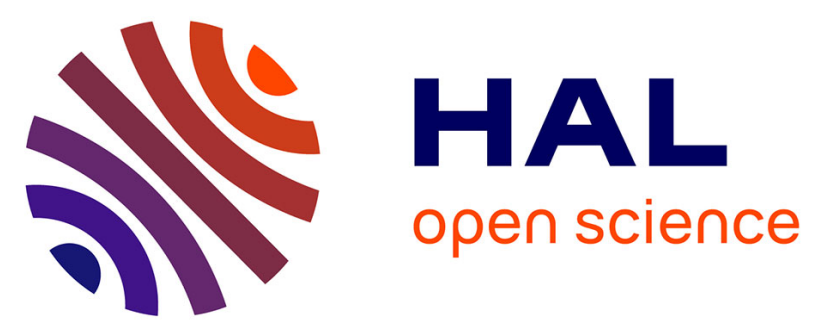

\title{
SMOS Radiometer in the 1400-1427-MHz Passive Band: Impact of the RFI Environment and Approach to Its Mitigation and Cancellation
}

E. Daganzo-Eusebio, R. Oliva, Yann H. Kerr, S. Nieto, Philippe Richaume, S. Mecklenburg

\section{To cite this version:}

E. Daganzo-Eusebio, R. Oliva, Yann H. Kerr, S. Nieto, Philippe Richaume, et al.. SMOS Radiometer in the 1400-1427-MHz Passive Band: Impact of the RFI Environment and Approach to Its Mitigation and Cancellation. IEEE Transactions on Geoscience and Remote Sensing, 2013, 51 (10), pp.4999-5007. 10.1109/TGRS.2013.2259179 . ird-00913353

\section{HAL Id: ird-00913353 https://hal.ird.fr/ird-00913353}

Submitted on 9 Dec 2013

HAL is a multi-disciplinary open access archive for the deposit and dissemination of scientific research documents, whether they are published or not. The documents may come from teaching and research institutions in France or abroad, or from public or private research centers.
L'archive ouverte pluridisciplinaire $\mathbf{H A L}$, est destinée au dépôt et à la diffusion de documents scientifiques de niveau recherche, publiés ou non, émanant des établissements d'enseignement et de recherche français ou étrangers, des laboratoires publics ou privés. 


\title{
SMOS Radiometer in the 1400-1427-MHz Passive Band: Impact of the RFI Environment and Approach to Its Mitigation and Cancellation
}

\author{
Elena Daganzo-Eusebio, Roger Oliva, Yann H. Kerr, Fellow, IEEE, Sara Nieto, Philippe Richaume, \\ and Susanne Martha Mecklenburg
}

\begin{abstract}
The Soil Moisture and Ocean Salinity (SMOS) radiometer operates within the Earth Exploration Satellite Service passive band at 1400-1427 MHz. Since its launch in November 2009, SMOS images are strongly impacted by radio frequency interference (RFI). So far $>500$ RFI sources distributed worldwide have been detected. Up to $42 \%$ of these RFIs could be suppressed thanks to the co-operation of the National Spectrum Management Authorities. Some of the strongest RFI sources might mask other weaker sources underneath, hence it is expected the total number of RFI detected may increase as strong ones are progressively identified and switched off. Most RFIs are located in Asia and Europe, which together hold $\sim 73 \%$ of the active sources and $>90 \%$ of the strongest interference. The areas affected by RFI may experience either an underestimation in the retrieved values of soil moisture and ocean salinity or data loss, with the associated detrimental impact on the scientific return. ESA and the teams participating in SMOS mission have put in place different strategies to alleviate this RFI situation.
\end{abstract}

Index Terms-Interference, radiometry, radio spectrum management.

\section{INTRODUCTION}

$\mathbf{T}$ HE Soil Moisture and Ocean Salinity (SMOS) mission is a joint program led by the European Space Agency (ESA) with participation of the Centre National d'Etudes Spatiales (CNES) in France and the Centro Para el Desarrollo Tecnológico Industrial (CDTI) in Spain. Its main scientific objective is to observe soil moisture over land and sea surface salinity over oceans [1]. Since its launch in November 2009, SMOS observations are being perturbed by radio frequency interferences (RFIs) that jeopardize part of its scientific retrieval in certain areas of the World, especially over continental areas in Europe, South-Eastern Asia,

Manuscript received September 13, 2012; revised January 20, 2013; accepted February 7, 2013.

E. Daganzo-Eusebio is with the European Space Agency, European Space Research and Technology Centre, Noordwijk 2200 AG, The Netherlands (e-mail: Elena.Daganzo-Eusebio@esa.int).

R. Oliva and S. Nieto are with the European Space Agency, European Space Astronomy Centre, Madrid E-28691, Spain (e-mail: roger.oliva.balague@esa.int; sara.nieto@esa.int).

Y. Kerr and P. Richaume are with Centre d'Etudes Spatiales de la BIOsphère, Toulouse Cedex 31401, France (e-mail: yann.kerr@ cesbio.cnes.fr; philippe.richaume@cesbio.cnes.fr).

S. M. Mecklenburg is with the European Space Agency, European Space Research Institute, Frascati 00044, Italy (e-mail: susanne.mecklenburg@ esa.int).

Color versions of one or more of the figures in this paper are available online at http://ieeexplore.ieee.org.

Digital Object Identifier 10.1109/TGRS.2013.2259179 and the Middle East. Detecting and flagging contaminated observations and contacting national authorities to localize and eliminate RFI sources emitting in the protected band present a continuous challenge. This paper describes the regulatory framework for the protection of remote sensors in the $1400-1427-\mathrm{MHz}$ frequency band, the effect RFI has on SMOS data and the different approaches considered to improve the detection, cancellation, and mitigation of the RFI contamination [2]. This paper also provides an overview of how the SMOS RFI scenario has evolved, worldwide and in particular over Europe, following the actions of National Spectrum Management Authorities and the cancellation of many of the RFI sources detected.

\section{International RegUlation fOR the PROTECTION} OF THE 1400-1427-MHz PASSIVE BAND

The Earth Exploration Satellite Service (EESS) for passive sensing has a primary frequency allocation in the $1400-1427 \mathrm{MHz}$ band and all emissions are prohibited in this band according to the ITU-R Radio Regulations (RR) footnote 5.340. In addition, the World Radiocommunication Conference 2007 (WRC-07) adopted Resolution 750 on the compatibility between the EESS-passive and relevant active services. As concerns the $1400-1427-\mathrm{MHz}$ band, Resolution 750 contains recommended levels of unwanted emissions applicable to the whole range of ITU-R services allocated in the adjacent bands (Fig. 1) and resolves to urge administrations to take all reasonable steps to ensure that unwanted emissions of active services do not exceed the specific recommended maximum levels, noting that EESS passive sensors provide worldwide measurements that benefit all countries.

The evidence of RFI at levels that prevent geophysical measurements is the rationale for having compulsory (not only recommended) limits to protect the purely passive bands. In Europe, the CEPT Electronic Communications Committee (ECC) approved in March 2011 a new decision $\mathrm{ECC} / \mathrm{DEC} /(11) 01$ on the protection of the EESS (passive) service in the $1400-1427-\mathrm{MHz}$ band. This ECC decision, which was proposed with the support of ESA, CNES, ANFR, and EUMETNET, translates the compatibility criteria recommended by ITU into mandatory limits and intends to give a clear signal to the international community about the recognition by CEPT of the societal and economical values 


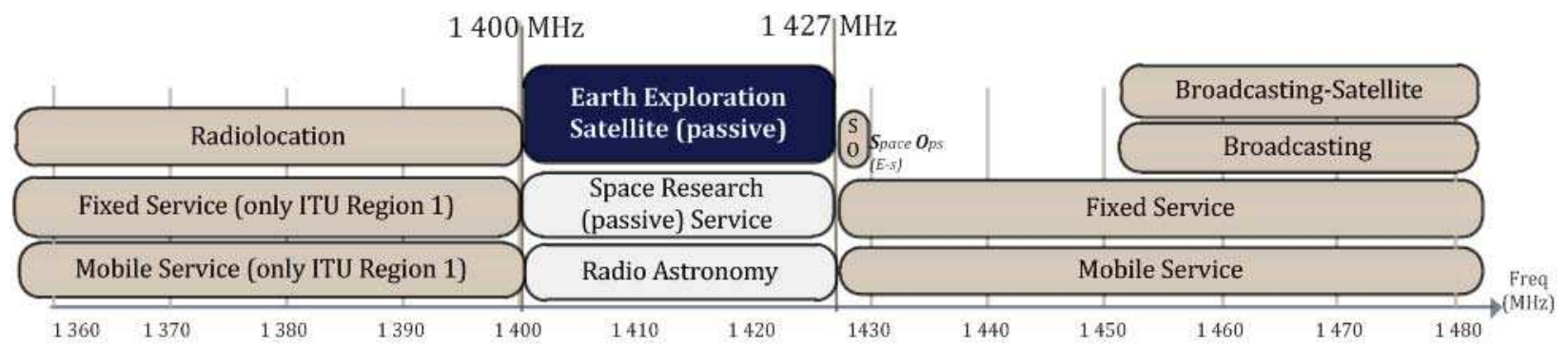

Fig. 1. ITU-R frequency allocations in the 1400-1427-MHz range and adjacent frequency bands [3].

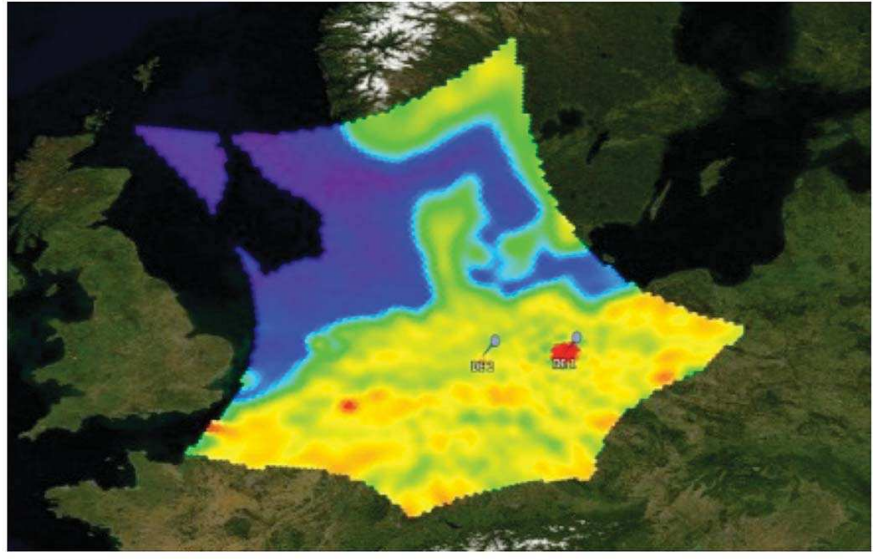

Brightness Temperature $[\mathrm{K}]$

$0.0 \quad 50.0 \quad 100.0150 .0200 .0250 .0300 .0350 .0$

Fig. 2. SMOS snapshot showing several RFI emissions detected in Central Europe on October 2010

of the EESS (passive) applications related to climate change and natural disasters prediction. The limits for unwanted emissions apply to stations in the active services operating in CEPT countries in the $1350-1400$ and $1427-1452-\mathrm{MHz}$ bands brought into use after January 1, 2012. Each CEPT administration decides at national level when the ECC decision is implemented. Currently up to ten European countries have already implemented this decision, which is being planned in some others [3]. SMOS, AQUARIUS and in particular future Earth Observation (EO) missions operating in the 1400-1427-MHz passive band, will benefit from this decision.

To increase the awareness of the impact of RFI in the passive sensors, the SMOS RFI issue was brought to the attention of the European Commission, who underlined the importance of strengthening the co-operation of all EU member states in the investigation of the RFI sources over their territories and of taking action to remove, as much as possible, the remaining interferences still being observed [4].

In addition, the Committee on Space Research (COSPAR) also recognized the importance of complying with the regulatory framework and requested all COSPAR national representatives to contact responsible agencies within their countries to take measures to eliminate unauthorized contaminating sources relating to the SMOS mission. Furthermore, ESA has reported the RFI problem faced by SMOS mission in several
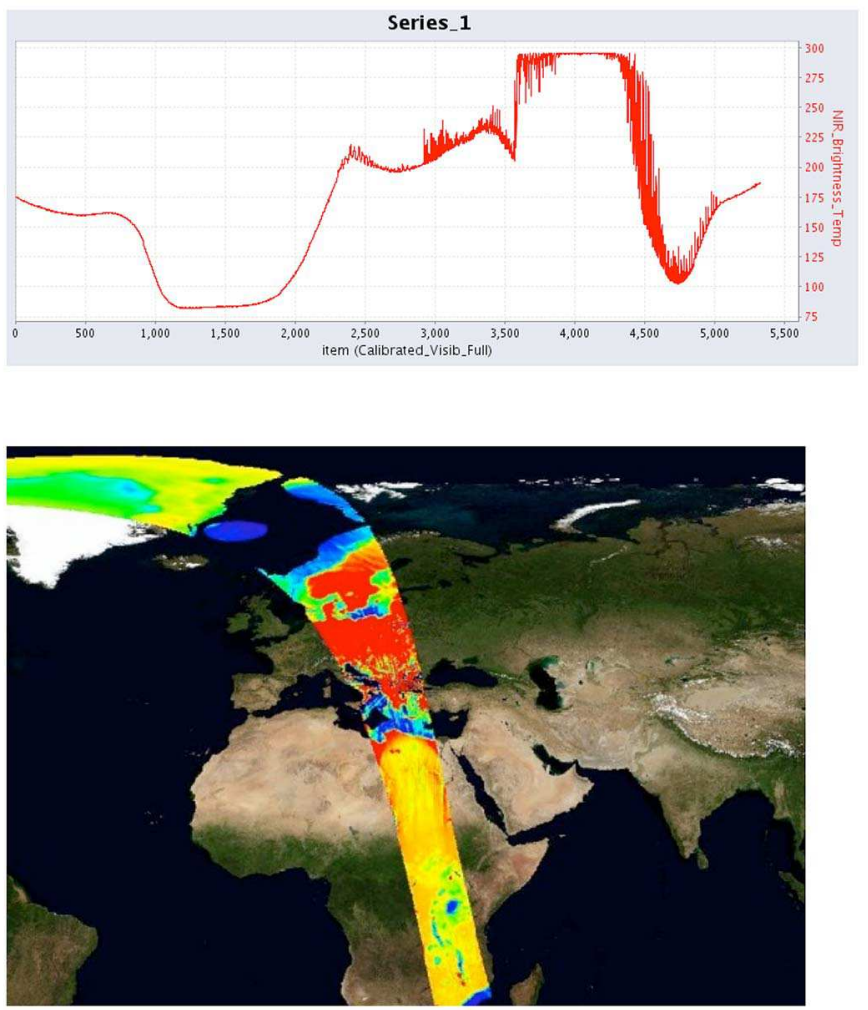

Fig. 3. Impact of very strong RFI emissions, observed as flares in Europe on April 2012 (bottom) and a plot showing the BT level of SMOS reference radiometer, indicating saturation of these receivers (top).

international forums such as the International Telecommunications Union (ITU), the Space Frequency Co-ordination Group (SFCG), the CEPT Frequency Management Working Group, and various scientific conferences (e.g., OCOSS, IGARSS, and EGU).

\section{SMOS RFI OBSERVATIONS}

\section{A. Type of RFI Emissions}

Man-made emissions within the passive band are observed by SMOS as strong point source emissions. The RFI is observed as a brightness temperature (BT) intensity that exceeds the emission radiated by natural sources. The maximum BT because of natural sources is the physical temperature of the source and the maximum ground temperature ever recorded so far is $\sim 338 \mathrm{~K}\left(65{ }^{\circ} \mathrm{C}\right)$. Therefore, BTs values $>340 \mathrm{~K}$ indicate that there is a man-made transmitter in the 


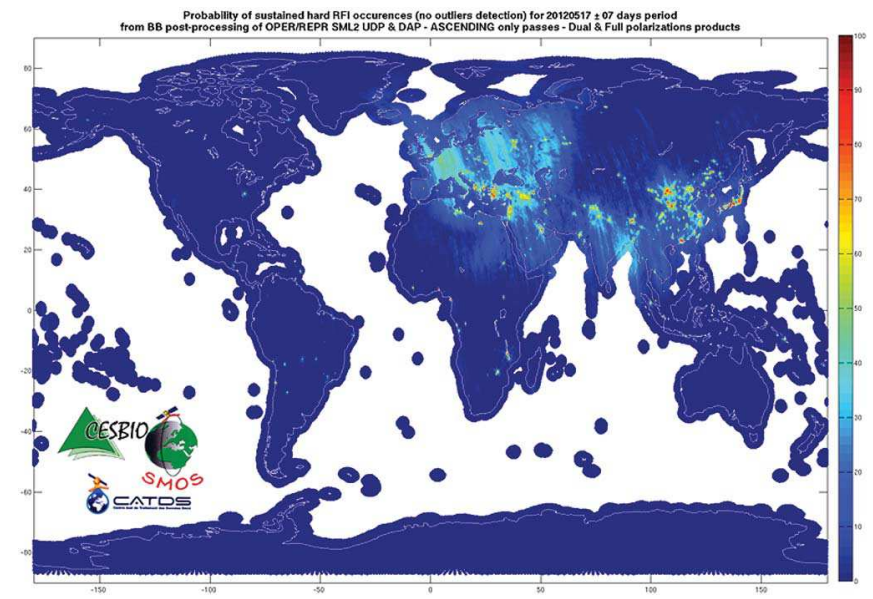

Fig. 4. Worldwide RFI contamination probability during the period of May 10-24, 2012.
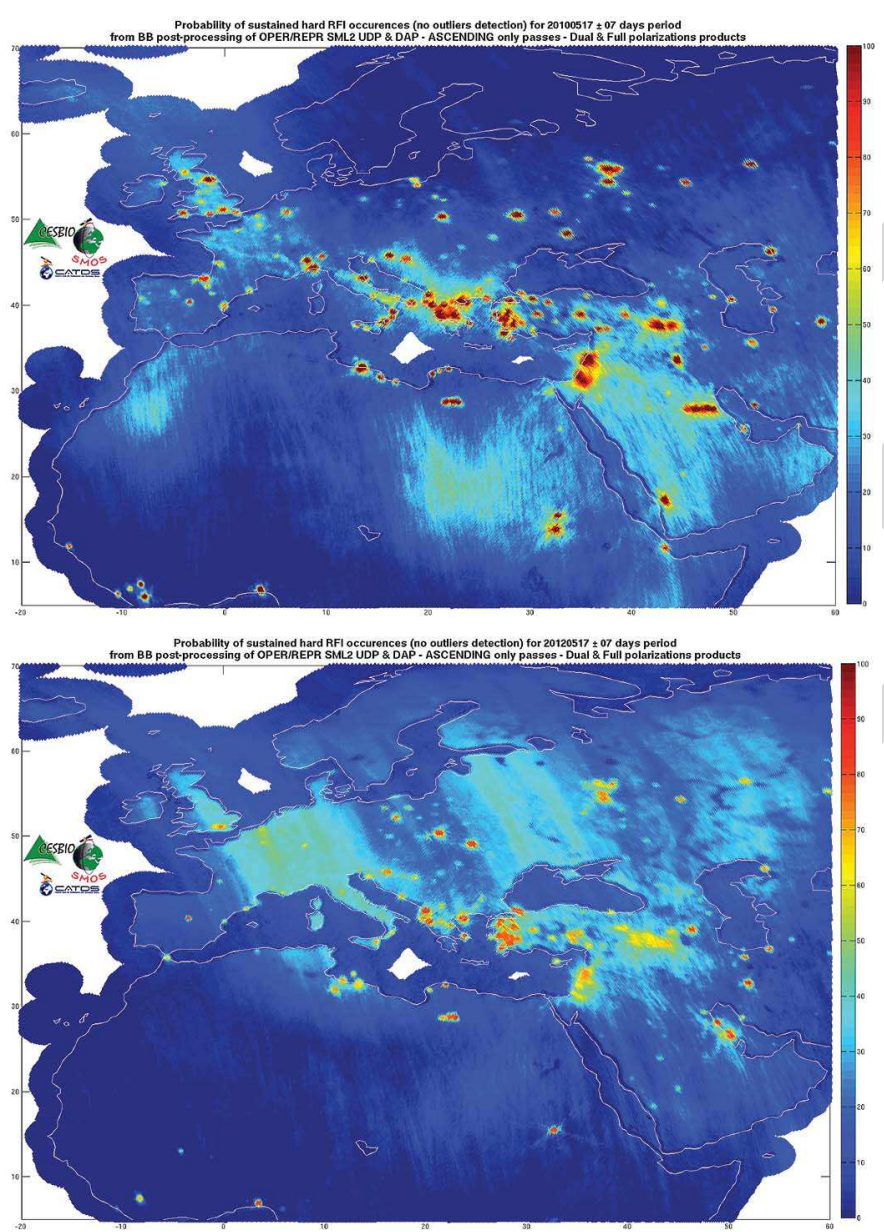

Fig. 5. Probability of sustained RFI occurrence over Europe during 2-weeks time-window (10-24 May) in 2010 (top) and 2012 (bottom).

band without any doubt. RFI emissions can be categorized as low, moderate, strong or very strong as follows.

1) Low RFI emissions have levels similar to natural sources and are difficult to detect, leading to incorrect physical retrieval.

2) Moderate RFI emissions are easily detectable but their effects are circumscribed to the on-ground emitter's
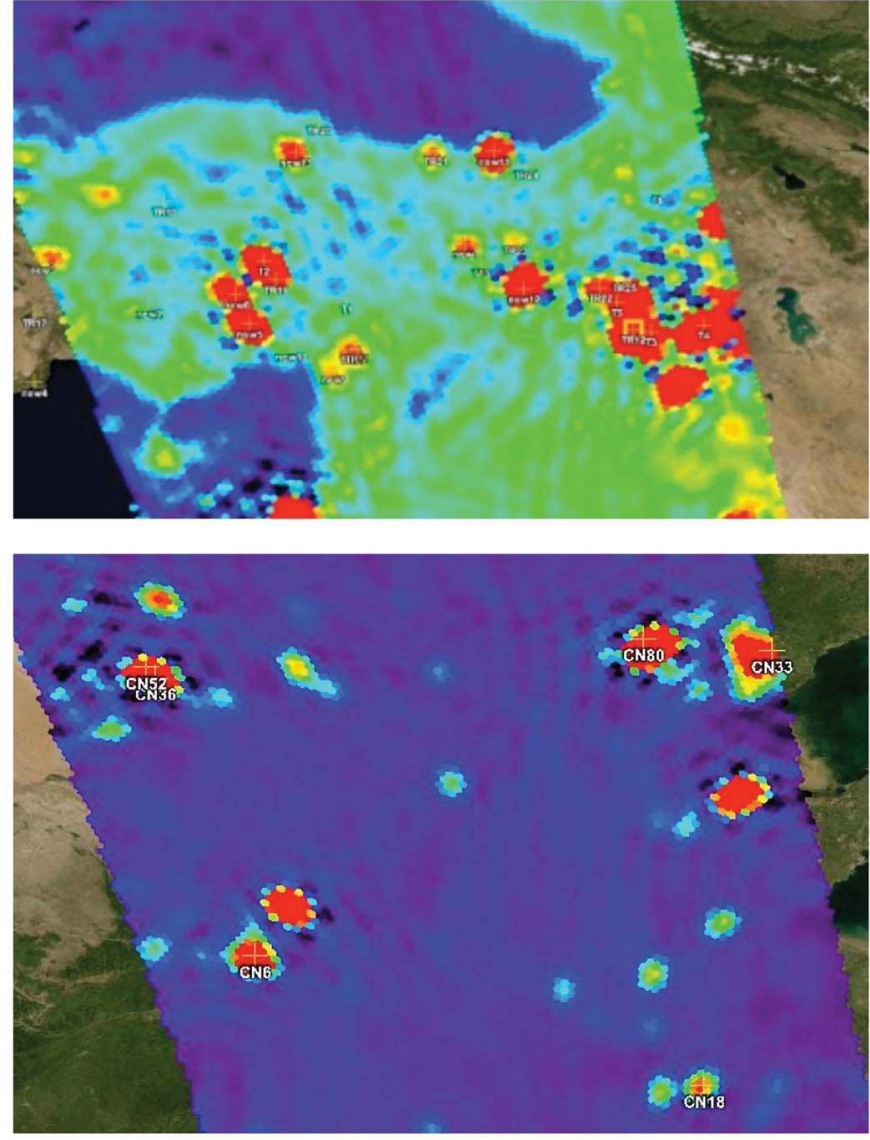

Fig. 6. SMOS images showing geolocation of RFI sources in the area of Turkey/Middle East on November 2011 (top) and over China on January 2012 (bottom).

location. The quality of the data will be negatively affected, with less data available for the retrieval leading to less accuracy (Fig. 2).

3) Strong RFI emissions influence larger areas through the secondary lobes tails, which need to be discarded for scientific retrieval, thus leading to a significant data loss.

4) Very strong RFI emissions essentially hide the full SMOS field-of-view and can blank out any natural signal over a range of several hundreds of kilometers, causing significant loss of data for scientific retrievals. In this respect, there are observed occasional but recurrent RFI flares in Europe that are able to saturate some of SMOS receivers as shown in Fig. 3.

The RFI sources observed by SMOS can be grouped into two main categories:

1) Illegal in-band emissions in the protected band. These are caused by unauthorized radiolinks, TV and FM broadcast stations, wireless monitoring cameras, malfunctioning DECT phone terminals, and more.

2) Excessive unwanted emissions from systems operating in the adjacent bands. These cause RFI because of outof-band and spurious emissions from radars and other transmitter systems.

The type of emission causing the interference cannot be confirmed based on the SMOS data alone. The feedback 


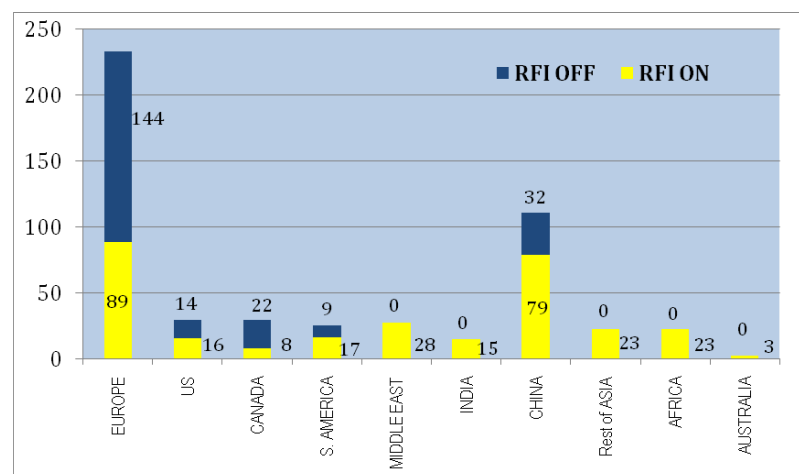

Fig. 7. Overview of SMOS RFI status OFF/ON in September 2012.

SMOS RFI Active: Worldwide Status by September 2012

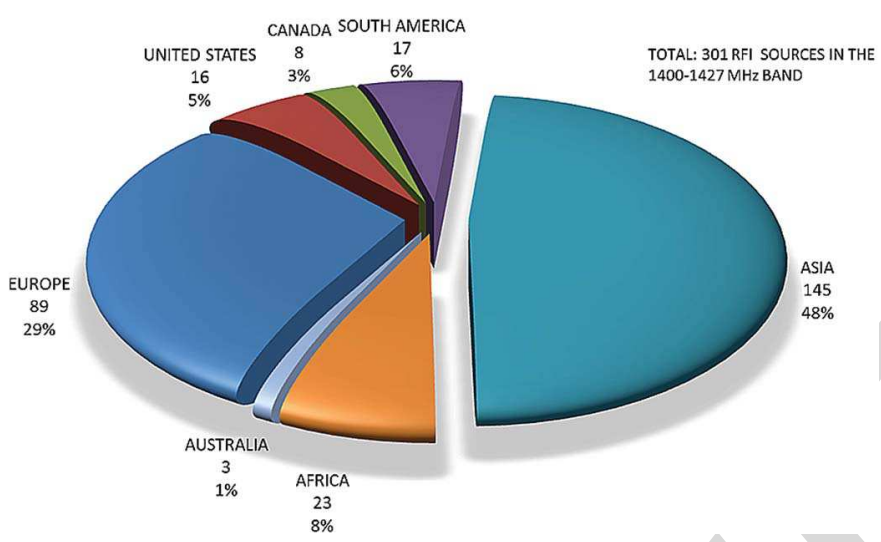

Fig. 8. Distribution of active RFI sources worldwide as of September 2012.

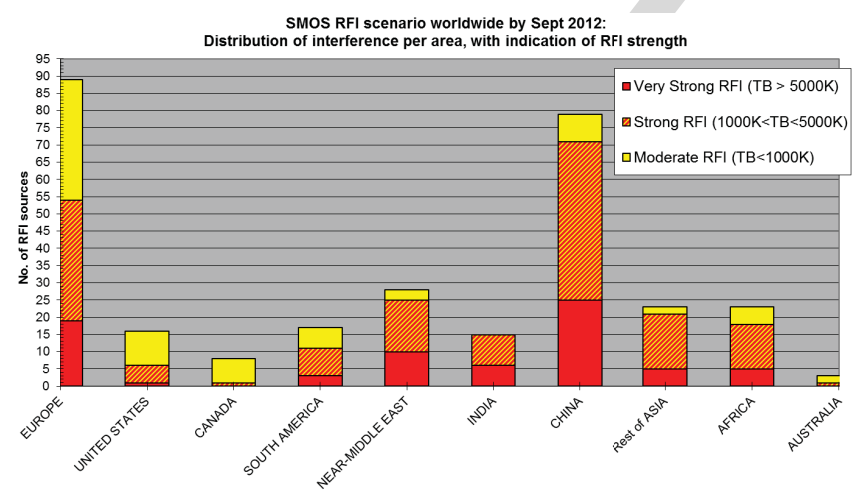

Fig. 9. Distribution of active RFI sources worldwide as of September 2012, classed into moderate, strong, and very strong emission levels.

received from the national spectrum management authorities is key to be able to better characterize the RFI sources and to further improve the interference detection, mitigation, and cancellation techniques.

\section{B. RFI Occurrence Probability Maps}

The Level-2 soil moisture processor allows retrieving statistical information of the SMOS pixels affected by RFI and this data can be presented as probability maps of RFI occurrences during a certain period of time.

The RFI detection included in soil moisture retrieval algorithms allows detecting strong emitters but also weaker

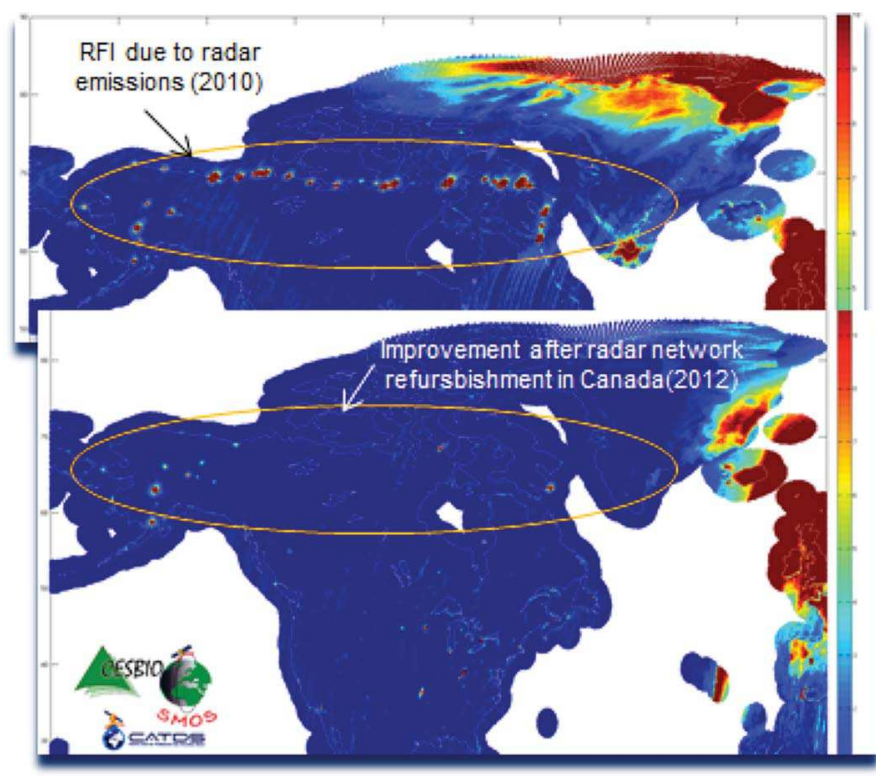

Fig. 10. RFI probability map over North America, showing improvement because of on-going action to refurbish L-Band radar stations in Canada.
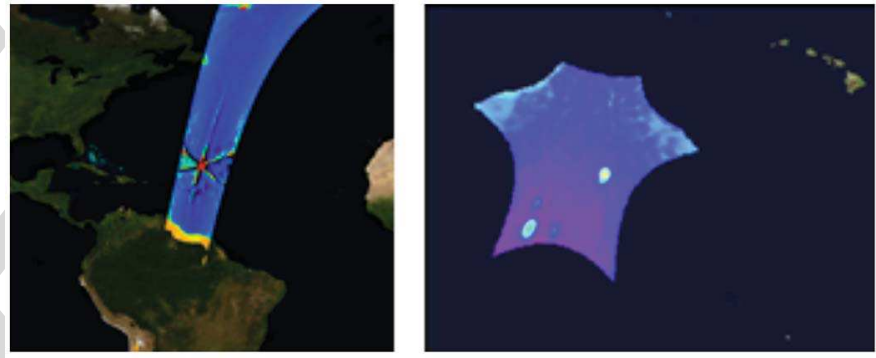

Fig. 11. Cases of RFI observed over the sea in the Caribe in 2010 (left) and near Hawaii in 2012 (right).

sources. As explained, strong sources are detected when their BTs are outside of the geophysical expectation range. This range uses variable thresholds dependent of the minimum/maximum physical earth surface temperature within the antenna footprints. This procedure is stricter than the traditional "maximum maximorum" $340 \mathrm{~K}$ fixed threshold and allows detecting lower BTs values as RFI sources if they are not geophysically plausible given the earth surface estimates (from ECMWF) and considering margins to avoid false alarms. Weaker RFI contaminations are detected through anomalous angular signature on the first Stokes parameter $\left(B T_{\mathrm{X}}+B T_{\mathrm{Y}}\right)$, which is expected not to change much with the incidence angle. Finally, when the soil moisture retrieval is attempted, the farthest outliers with respect to the model solution are eliminated as (possible) soft RFI sources (larger than four times the BTs radiometric uncertainties).

The basis of probability maps is to count the number of BTs considered as contaminated per pixel and orbit and to accumulate counters as the beginning of the mission in daily global files maps. These files are called as DGG current RFI and hold the three counters: $\mathrm{NRFI}_{\mathrm{X}}$, NRFI $\mathrm{N}_{\mathrm{Y}}$, and NSNAP. NRFI $_{X}$ (resp. NRFIY) are the number of BTs detected as contaminated on X (resp. Y) antenna polarization, whereas 


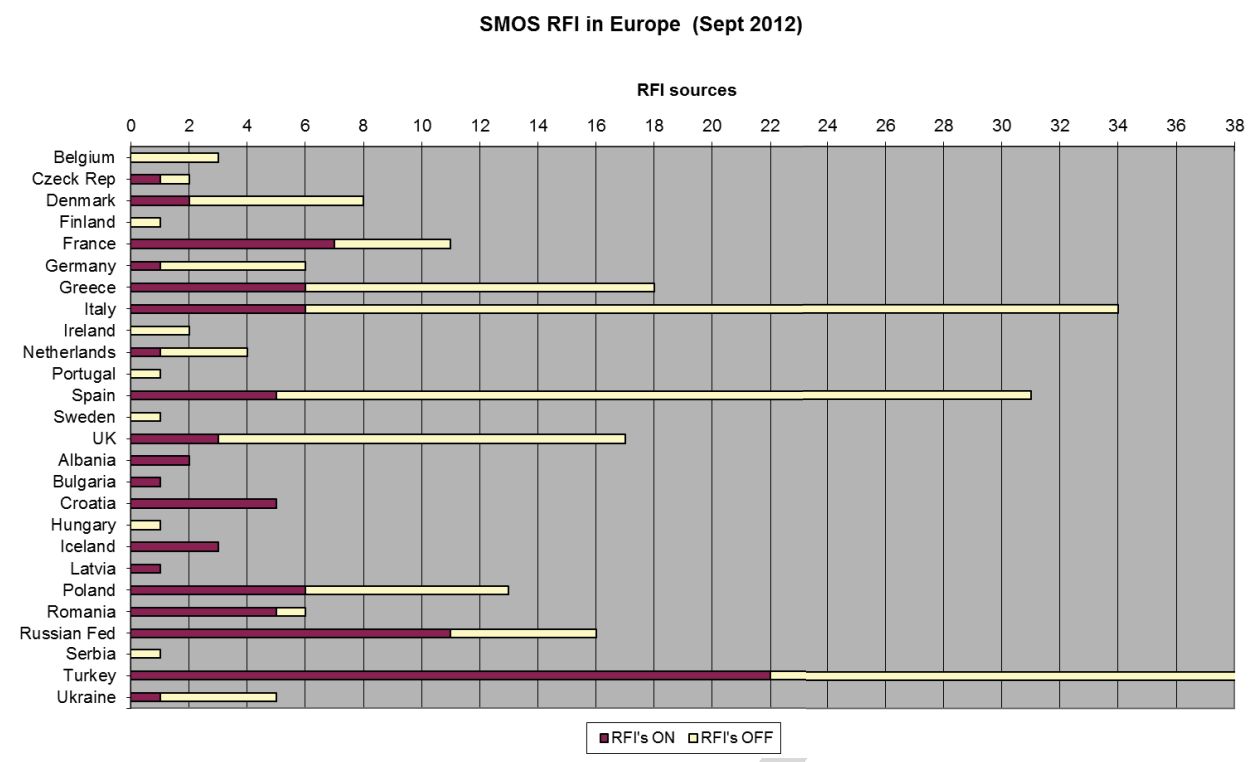

Fig. 12. Distribution active and switched off RFI sources over Europe by country (status September 2012).

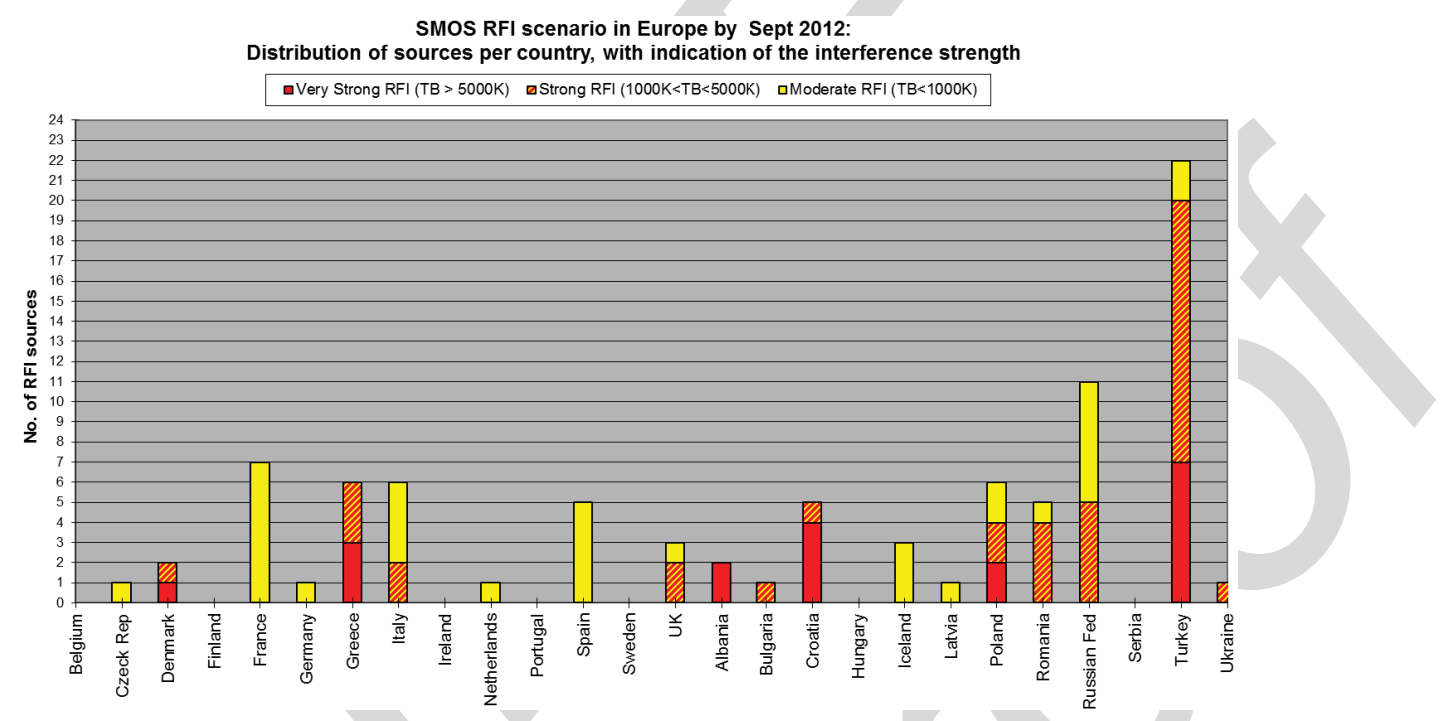

Fig. 13. Distribution of active RFI sources over Europe as of September 2012, classed into moderate, strong, and very strong emission levels.

NSNAP is the total number of observed BTs. Then, $P=$ $\left(\mathrm{NRFI}_{\mathrm{X}}+\mathrm{NRFI}_{\mathrm{Y}}\right) / \mathrm{NSNAP}$ defines a probability of RFI occurrences as the beginning of the mission up to the validity date of a given DGG current RFI map. By differentiating two DGG current RFI counters maps for two dates, the probability of RFI occurrences can be computed for the specific time period that these two dates define. This is shown in the three following probability maps for 15 days time window at various dates.

The worldwide RFI probability map during the period May 10-24, 2012 is shown in Fig. 4, and the detailed maps over Europe for 2010 and 2012 are shown in Fig. 5. The color bar ranges from red (100\%), indicating that RFIs are always present and means that no BT measurements were kept at all during 15 days, to deep blue, indicating none to very low probability and thus almost all BT measurements were kept as usable for retrieval. Intermediate values indicate a high proportion of RFI presence but do not tell when the occurrences appeared within the time window considered. For the 15 days time window illustrated in these maps, a probability of $50 \%$ (green) is equally obtained by 7.5 days of continuous strong emissions followed by 7.5 days of no emission at all or by alternating one day with strong RFI followed by one day RFI off or any other combinations.

These maps do not include outliers to models but only the radiometric detection to avoid any controversy about the validity of models that may create false alarms. In the same spirit, reasonable margins in thresholds and the use of the radiometric uncertainty are taken into consideration for the detection to avoid false alarms. The presented maps, though scary as they are, must be considered optimistic; the reality is certainly worse because of the margins taken, of the fact that the stronger RFI sources may be masking weaker RFI emitters 


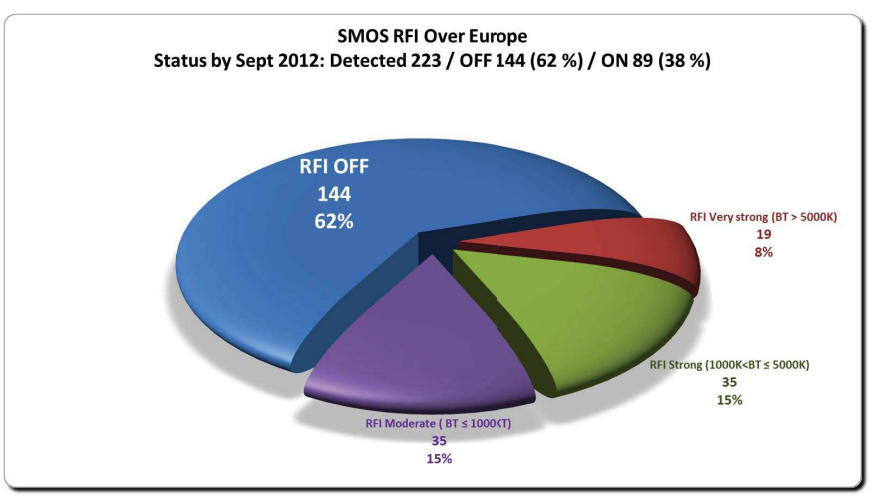

Fig. 14. Global statistics of SMOS RFI over Europe. Status of September 2012.

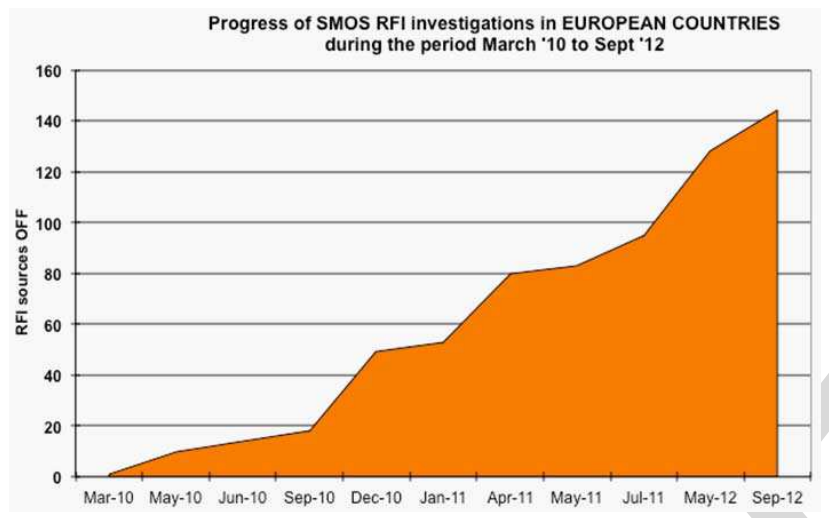

Fig. 15. Evolution of SMOS RFI investigations over Europe in co-operation with the National Spectrum Management Authorities as of September 2012.

and of the difficulty in detecting RFI emissions of moderate strength very close to BT values from natural sources.

\section{RFI Detection and Geolocation Process}

SMOS L1c products provide geolocated measurements of BT. These measurements integrate the radiation received at the satellite every $1.2 \mathrm{~s}$.

A team of data analysts regularly scans these SMOS images and the probability maps presented in the previous section for new RFI sources. Whenever a RFI is detected, a semiautomatic algorithm [5] analyzes several SMOS passes over that area. The objective of the algorithm is to estimate, as best as possible, the on-ground location of the RFI and its BT intensity (see Fig. 6). This information is then transmitted to the national spectrum management authorities of the country. These will initiate investigations about the location and origin of the RFI source and will take the necessary actions to either switch off the emitter or repair malfunctioning equipment until the interference is eliminated.

Even though SMOS spatial resolution $(35-55 \mathrm{~km})$ is not very adequate for this purpose, the algorithm relies on the large amount of observations to improve the accuracy of the geographical co-ordinates of the antenna emitter. Considering that during one pass, each point on-ground is measured several times under different incidence angles (as the satellite moves forward) and that at least two weeks of measurements over that
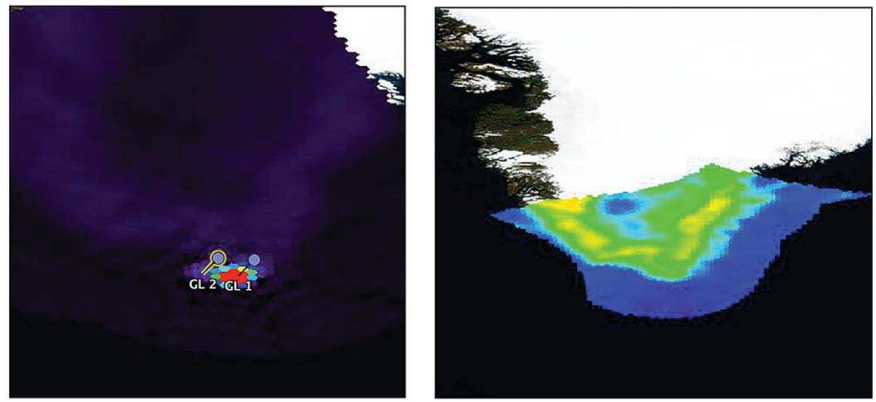

Fig. 16. Evolution of SMOS RFI investigations over Greenland [December 2010 (left) to March 2011 (right)].
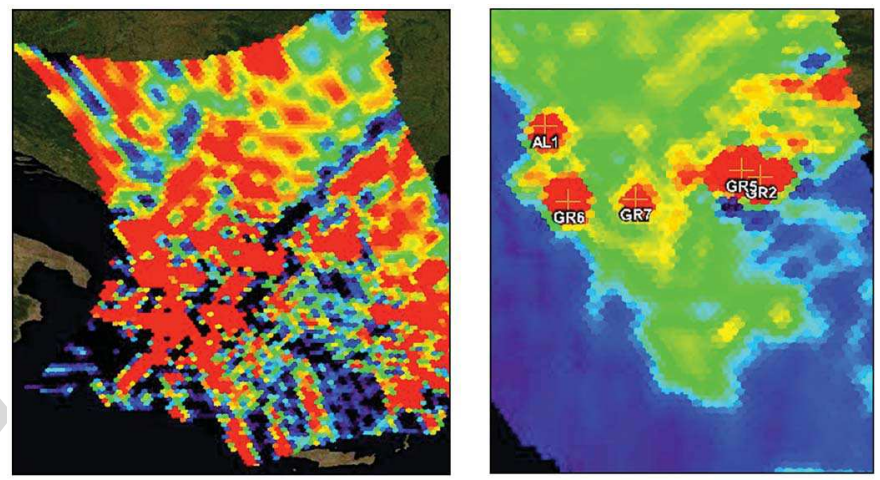

Fig. 17. Evolution of SMOS RFI investigations over Greece [June 2010 (left) to April 2011 (right)].

region (i.e., $\sim 10$ passes) are used to infer the RFI position, the final accuracy of this technique is better than $5 \mathrm{~km}$ in the majority of the cases.

Other characteristics that can be derived in this geolocation process are the RFI emitter pointing direction and periodicity (e.g., pulsed emissions from scanning radars, nonpermanent sources, continuous emissions, and so on).

The BT associated to each RFI only aims to characterize a first-order estimation of the intensity and to prioritize within the RFIs detected in one particular country which ones are most harmful to SMOS measurements. The majority of the RFI sources correspond to terrestrial emitters with low elevation, whereas the satellite measurements correspond to almost zenith observations. Therefore, the BT values measured do not fully represent the total power transmitted by the interference source in the passive band.

A very important aspect of the RFI detection process, together with the accuracy, is reliability. The aim is not to provide any false alarm detection to the spectrum management authorities, which could involve the mobilization of a ground monitoring patrol team looking for an inexistent RFI. This situation would discourage the national authorities' efforts to improve SMOS RFI situation over their territories.

\section{APPROACHES to IMPROVE SMOS RFI SituATION}

\section{A. General Description of the Approaches Considered}

Several strategies are put in place to improve scientific retrieval of SMOS team under the RFI scenario observed worldwide as follows: 

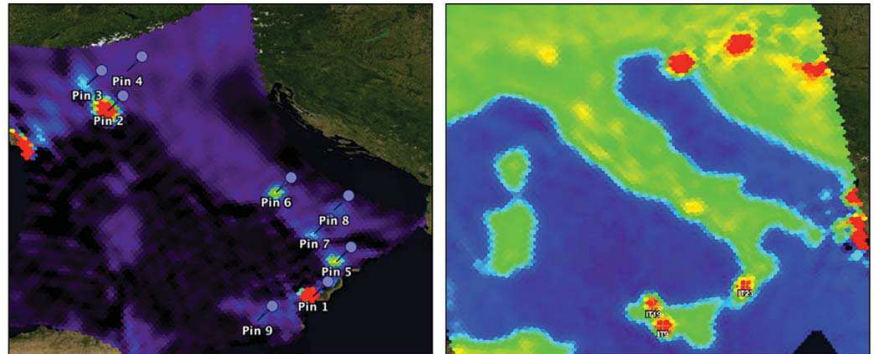

Fig. 18. Evolution of SMOS RFI investigations over Italy [July 2010 (left) to April 2011 (right)].
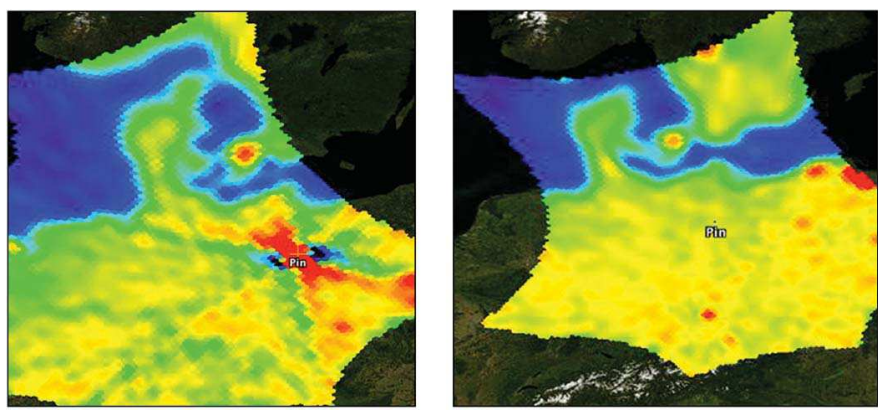

Fig. 19. Evolution of SMOS RFI investigations over Germany [January 2011 (left) to February 2011 (right)].

1) In the short and medium term:

a) to report the detected RFI sources to the National Spectrum Management Authorities and request for their support to initiate investigations. Main outcome of this initiative is the cancellation of those RFI sources because of emitters that do not comply with ITU regulations;

b) to localize and flag the RFI contamination in the respective Level-1 data product, thus avoiding that this data is used for the retrieval of Level-2 data products. Flagging techniques have associated an important loss of data although they increase the reliability in the scientific retrieved data;

c) to investigate new RFI mitigation algorithms. New approaches to mitigate or cancel the RFI impact are under development and preliminary testing is being conducted. Interference mitigation techniques have either big uncertainties associated to their corrections or imply a degradation of certain instrument characteristics, such as spatial resolution, in favour, for example, of a reduction of the synthetic beam secondary side-lobes. Therefore, the real benefit of such techniques is still to be proved.

2) In the medium and long term:

a) to increase the awareness of the international telecom community about the ITU radio-regulations, both in terms of prohibiting any emissions in the passive band, and also in terms of respecting the maximum levels recommended for unwanted emissions (in the passive band) because of active services in adjacent bands. It is important to remember that the removal of strong RFI sources does not mean that the band is entirely free
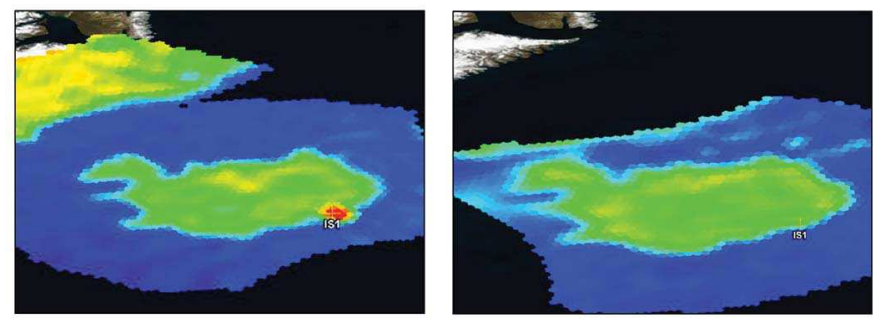

Fig. 20. Evolution of SMOS RFI investigations over Iceland [March 2011 (left) to April 2011 (right)].
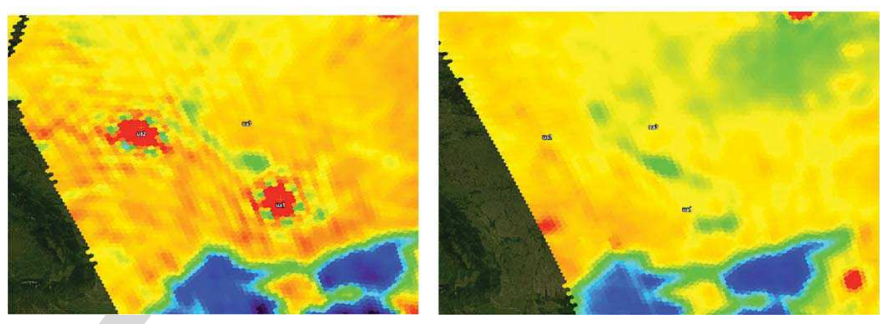

Fig. 21. Evolution of SMOS RFI investigations over Ukraine [December 2010 (left) to August 2011 (right)].

of interference, as low level RFI can still be present and create erroneous data.

\section{B. Worldwide Evolution of SMOS RFI}

ESA regularly reports the interference cases to the spectrum management authorities of the different countries so that they can initiate investigations, identify the type of emitter and take appropriate actions.

Following a careful analysis of the retrieved data, ESA prepares a RFI catalog/country, containing detailed information of the geolocation, BT measurements, and characteristics of the RFI source for all interferences detected over the territory. This information is typically provided together with a snapshot of SMOS observations over the area of interest. The spectrum management authorities normally distribute the information on RFI sources/regions, and then delegate regional office the task of investigation and on-site monitoring of the reported RFI locations.

An overall SMOS RFI catalog is updated regularly and allows ESA to keep track of the process in the identification and switching off of RFI sources. The investigation of RFIs is often an iterative process that requires the co-operation of the authorities and the co-ordination and regular RFI status updates provided by SMOS RFI team. This procedure is timeconsuming and not always successful, but has proven to be effective to improve the interference scenario over extensive areas.

So far ESA has contacted 45 administrations and reported $>500$ RFI sources, most of them located in Europe and Asia. Approximately $42 \%$ of the RFI sources were successfully identified and switched off. Fig. 7 shows an overview of the worldwide progress in the investigations since early 2010 until now. A significant improvement is observed in Europe (144 RFI off), Canada (22 RFI off), and the United States of America (14 RFI off). Since early 2012 some improvement 

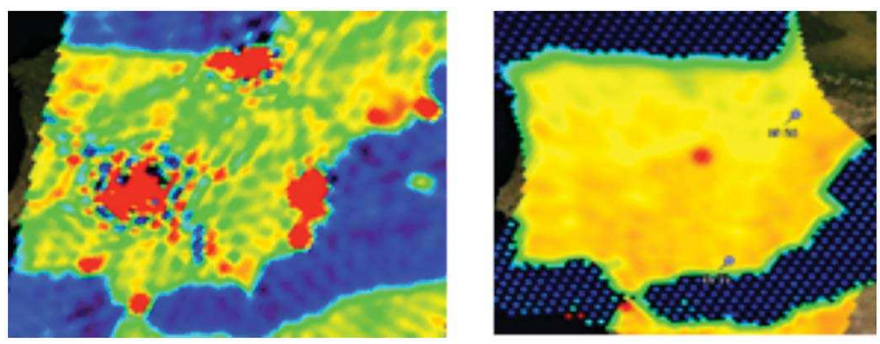

Fig. 22. Evolution of SMOS RFI investigations over Spain [January 2010 (left) to June 2012 (right)].

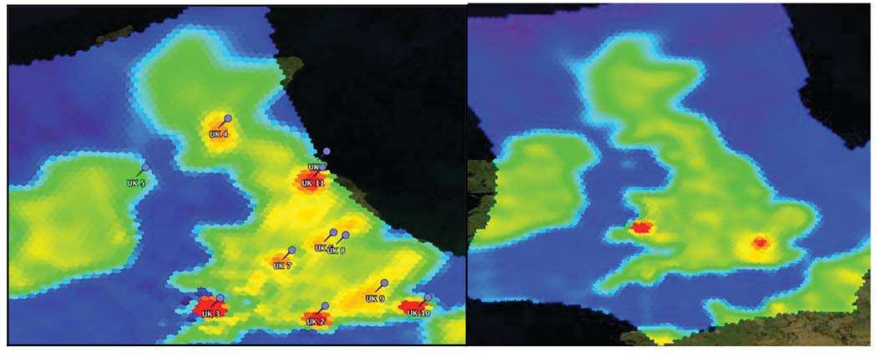

Fig. 23. Evolution of SMOS RFI investigations over United Kingdom [June 2010 (left) to January 2012 (right)].

is also observed in Asia, with 32 RFI sources switched off in China, although the continent still remain much polluted by RFI and with the strongest emitters in the passive band. By September 2012, there are up to 300 RFIs still active worldwide and the more polluted areas are Middle East, China, and some areas in Europe. See the distribution worldwide of the active RFI sources in Figs. 8 and 9.

The out-of-band emissions from radar systems are confirmed as RFI sources in numerous cases. The adjustment of some technical parameters or repair of malfunctioning modules has fixed the problem in several occasions. In other cases, the refurbishment of the radar station was necessary to ensure compliance with the unwanted emissions maximum levels set by ITU-R regulations. Because of the commitment of the national authorities the situation concerning radar interferences is improving in several countries, as was the case of Canada, shown in Fig. 10.

Continental regions are not the only ones affected by RFI. Fig. 11 shows two cases of RFI emitted from boats observed near the Caribbean islands (2010) and more recently in the Pacific Ocean, near Hawaii (2012).

\section{Evolution of SMOS RFI in Europe}

Since early 2010, > 220 RFI were detected over Europe and 144 RFIs were successfully switched off because of the cooperation of the National Spectrum Management Authorities. Fig. 12 shows an overview of the number of RFI sources on/off/country, and Fig. 13 shows the distribution/country in terms of BT intensity (moderate, strong, and very strong) for those sources active in September 2012. Finally, Fig. 14 shows the global statistics as of Europe.

The authorities of up to 26 European countries are cooperating with ESA in the investigation of the RFI over their territories. The evolution and the results obtained from their involvement are shown in Fig. 15.

A significant improvement is observed since SMOS launch and this is noticeable when comparing the satellite snapshots before and after actions were taken to cancel the RFI. See for example the cases of Greenland (Fig. 16), Greece (Fig. 17), Italy (Fig. 18), Germany (Fig. 19), Iceland (Fig. 20), Ukraine (Fig. 21), Spain (Fig. 22), and United Kingdom (Fig. 23).

\section{CONCLUSION}

This paper showed that it is essential to protect the passive band 1400-1427 MHz from both illegal in-band emissions and excessive unwanted emissions. While the solution of the RFI because of illegal emissions can be achieved with the co-operation of the national authorities, the solution of the excessive unwanted emissions problem would also require regulatory action and compliance with the levels adopted in ITU-R Resolution 750 (WRC-07). This effort had to be continued and intensified by raising concern among the different countries and organizations about the impact of RFI on scientific observations in particular from potential new services or systems that could be authorized in the adjacent bands.

\section{ACKNOWLEDGMENT}

The authors would like to thank various scientific and industrial teams working together to alleviate the RFI situation (ACRI, CESBIO, DEIMOS, DTU, ESA, IFREMER, INSA, IRAP, and UPC), and also would like to thank their valuable contributions and continuous encouragement to improve the RFI environment received from SMOS Team, in particular M. M. Neira, SMOS Principal Payload Engineer and E. Marelli, ESA Frequency Manager. For the continuous work and support for the protection of the EESS passive bands J. Pla from CNES and P. Tristant from EUMETNET are also appreciated. The support and involvement in the investigation of RFI sources of all National Frequency Regulation Authorities is a key factor to ensure the improvement of SMOS RFI scenario, and ESA is very thankful to all Administrations for this support. In particular, the authors would like to recognize the excellent results achieved in Spain thanks to the co-operation of J. C. Vallejo, from the Dirección General de Telecomunicaciones (Spain). For their contribution to improve the RFI situation over their countries, the authors would like to also recognize the following persons and institutions: G. Ducheyne and $\mathrm{F}$. Vindevoghel of the Belgisch Instituut voor postdiensten and telecommunicatie and R. De Wiest of the Section Radar at ATCC Belgium Air component (Belgium); H. Blume, of the Danish National IT and Telecom Agency (Denmark); J. Kallio of the Finnish Communications Regulatory Authority and J. Kainulainen at Aalto University (Finland); J. Guyomard from ANFR (France); J. Nitschke of BNetZA and U. Birkenstok of the German Air Force Command (Germany); C. Kechribaris of the Spectrum Monitoring Department EETT (Greece); D. Spoto of the Ministero dello Sviluppo Economico and F. Biondi of the Defense Ministry (Italy); V. Ernir Axelsson of the Icelandic Coast Guard and T. Jónasson of the Post and Telecom Administration of Iceland; M. van Rouwendal 
of the Ministerie van Defensie and L. Ket of the Dutch radiocommunications agency (The Netherlands); B. Dudhia of OfCom (UK); I. Gepko of the Ukrainian State Center of Radio Frequencies (UCRF), Zeng and Zhao (SRRC China), J. Andrzejczak of the Department of Spectrum Control at UKE (Poland), E. Cherian of Federal Comms Commission (United States); and Ly Bun-Ret and A. Ongaro, of the Spectrum, Information Technologies, and Telecommunications Sector (Canada).

\section{REFERENCES}

[1] S. Mecklenburg, M. Drusch, Y. Kerr, J. Font, M. Martin-Neira, S. Delwart, G. Buenadicha, N. Reul, E. Daganzo-Eusebio, R. Oliva, and R. Crapolicchio, "ESA's Soil Moisture and Ocean Salinity mission: An overview after one year of operations," IEEE Trans. Geosci. Remote Sens., vol. 50, no. 5, pp. 1345-1356, May 2012.

[2] R. Oliva, E. Daganzo-Eusebio, Y. H. Kerr, S. Mecklenburg, S. Nieto P. Richaume, and C. Gruhier, "SMOS radio frequency interference scenario: Status and actions taken to improve the RFI environment in the 1400-1427-MHz passive band," IEEE Trans. Geosci. Remote Sens., vol. 50, no. 5, pp. 1427-1439, May 2012.

[3] (2011). Implementation Status for Decision ECC/DEC/(11)01 [Online]. Available: http://www.erodocdb.dk/doks/implement_doc_ adm.aspx?docid $=2398$

[4] European Commission Radio Spectrum Committee. (2010). Update from France on the Interference to SMOS Satellite Operating Within the EESS (Passive) Frequency Band 1400-1427 MHz [Online]. Available: http://ec.europa.eu/information_society/policy/ecomm/radio_spectrum/_ document_storage/rsc/rsc34_public_docs/rscom10_70.pdf

[5] R. Oliva, S. Nieto, and F. Felix, "RFI detection algorithm: Accurate geolocation of the interfering sources in SMOS images," IEEE Trans. Geosci. Remote Sens., 2013, to be published.

Elena Daganzo-Eusebio received the M.Sc. degree in telecommunication engineering from the Polytechnic University of Madrid, Madrid, Spain.

She joined the European Space Agency (ESA), Operations Center, Darmstadt, Germany, in 1992, as a Ground Segment Systems Engineer and participated in the preparation of the ESA ground network to support LEOP and mission operations. Since 1996, she has worked in several areas with the European Space Research and Technology Centre, first as TT\&C and RF System Engineer with the Technical Directorate and since 2009 in Frequency Management Engineer in the Directorate of Earth Observation Programmes. She analyzes the requirements and constraints of EO missions with respect to frequency allocation and interference and monitors the evolution of the frequency needs for future missions. She participates in the work of technical committees in the frame of ITU, CEPT, and SFCG. She is following up the contacts with the National Frequency Management Administrations in order to improve SMOS RF interference environment.

Roger Oliva received the M.S. degree in telecommunication engineering from the Polytechnic University of Catalonia, Catalonia, Spain, and the M.S. degree in astronomy (D.E.A.) degree from Barcelona University, Barcelona, Spain.

He has worked on several space and astronomy projects, including Mars Express, astronomical microwave observatories and in the design of advanced telecommunications satellite payloads. Since 2007, he has been a Calibration Engineer for the European Space Agency, Earth Observation satellite SMOS.
Yann H. Kerr (M'88-SM'01-F'13) received the Engineering degree from Ecole Nationale Supérieure de l'Aéronautique et de l'Espace, the M.Sc. degree in electronics and electrical engineering from Glasgow University, Glasgow, U.K., and the Ph.D. degree from the Astrophysique Gophysique et Techniques Spatiales, Université Paul Sabatier, Toulouse, France.

$\mathrm{He}$ is currently the Director of Centre d'Etudes Spatiales de la BIOsphère, Toulouse. He was an EOS Principal Investigator (interdisciplinary investigations) and PI and precursor of the use of the SCAT over land. In 1990, he started to work on the interferometric concept applied to passive microwave earth observation and was subsequently the science lead on the MIRAS project for ESA. In 1997, he proposed the SMOS Mission, the natural outcome of the previous MIRAS work. He is currently involved in the exploitation of SMOS data, in the Cal Val activities and related level 2 soil moisture and level 3 and 4 developments. He is working on the SMOS next concept and involved in both the Aquarius and SMAP missions. He is a Distinguished Lecturer for GRSS. His current research interests include theory and techniques for microwave and thermal infrared remote sensing of the Earth, with an emphasis on hydrology and water resources management.

Dr. Kerr was a recipient of the World Meteorological Organization 1st Prize (Norbert Gerbier), the USDA Secretary's Team Award for Excellence (Salsa Program), the GRSS certificate of recognition for leadership in development of the first synthetic aperture microwave radiometer in space and success of the SMOS mission.

Sara Nieto received the B.S. degree in computer science, specializing in information systems development and artificial intelligence from the Universidad Carlos III de Madrid, Madrid, Spain.

She has been a part of the SMOS Operations Team, European Space Astronomy Centre, Madrid, since April 2010, where she provides support on radio frequency interference detection.

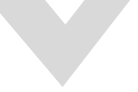

Philippe Richaume received the Engineer degree in computer, electronic, and automatic from Ecole Supérieure d'Informatique, Electronique et Automatique, Paris, France, in 1990, the M.Sc. degree in computer sciences and artificial intelligence from Paul Sabatier University, Toulouse, France, in 1991, and the Ph.D. degree in computer sciences and applied mathematics from CNAM, Paris, 1996.

He has worked in various geophysical laboratories, putting to test advanced computer science and applied mathematics paradigms against real problems, particularly in the remote sensing context. He is currently with the Centre d'Etudes Spatiales de la BIOsphère, Toulouse, France. His current research interests include nonlinear modeling and inverse problem, particularly using artificial neural networks, such as for a radio receiver real time controller dedicated to solar wind plasma line tracking onboard the WIND/WAVES spacecraft, or for direct-inverse modeling of ocean surface wind from ERS $1 / 2$ scatterometer or biophysical parameters, LAI, chlorophyll, from POLDER optical directional reflectance, or using traditional approaches like for soil moisture retrieval from SMOS brightness temperature.

Susanne Martha Mecklenburg received the M.S. degree in hydrology from the Technical University of Dresden, Dresden, Germany, and the Ph.D. degree in atmospheric science from the Swiss Institute of Technology, Zurich, Switzerland.

She joined the European Space Research Institute, European Space Agency (ESA), Frascati, Italy, in 2007, to take up the position of the SMOS Mission Manager. Before joining ESA, she was with the British National Space Centre, U.K. 


\title{
SMOS Radiometer in the 1400-1427-MHz Passive Band: Impact of the RFI Environment and Approach to Its Mitigation and Cancellation
}

\author{
Elena Daganzo-Eusebio, Roger Oliva, Yann H. Kerr, Fellow, IEEE, Sara Nieto, Philippe Richaume, \\ and Susanne Martha Mecklenburg
}

\begin{abstract}
The Soil Moisture and Ocean Salinity (SMOS) radiometer operates within the Earth Exploration Satellite Service passive band at 1400-1427 MHz. Since its launch in November 2009, SMOS images are strongly impacted by radio frequency interference (RFI). So far $>500$ RFI sources distributed worldwide have been detected. Up to $42 \%$ of these RFIs could be suppressed thanks to the co-operation of the National Spectrum Management Authorities. Some of the strongest RFI sources might mask other weaker sources underneath, hence it is expected the total number of RFI detected may increase as strong ones are progressively identified and switched off. Most RFIs are located in Asia and Europe, which together hold $\sim 73 \%$ of the active sources and $>90 \%$ of the strongest interference. The areas affected by RFI may experience either an underestimation in the retrieved values of soil moisture and ocean salinity or data loss, with the associated detrimental impact on the scientific return. ESA and the teams participating in SMOS mission have put in place different strategies to alleviate this RFI situation.
\end{abstract}

Index Terms-Interference, radiometry, radio spectrum management.

\section{INTRODUCTION}

$\mathbf{T}$ HE Soil Moisture and Ocean Salinity (SMOS) mission is a joint program led by the European Space Agency (ESA) with participation of the Centre National d'Etudes Spatiales (CNES) in France and the Centro Para el Desarrollo Tecnológico Industrial (CDTI) in Spain. Its main scientific objective is to observe soil moisture over land and sea surface salinity over oceans [1]. Since its launch in November 2009, SMOS observations are being perturbed by radio frequency interferences (RFIs) that jeopardize part of its scientific retrieval in certain areas of the World, especially over continental areas in Europe, South-Eastern Asia,

Manuscript received September 13, 2012; revised January 20, 2013; accepted February 7, 2013.

E. Daganzo-Eusebio is with the European Space Agency, European Space Research and Technology Centre, Noordwijk 2200 AG, The Netherlands (e-mail: Elena.Daganzo-Eusebio@esa.int).

R. Oliva and S. Nieto are with the European Space Agency, European Space Astronomy Centre, Madrid E-28691, Spain (e-mail: roger.oliva.balague@esa.int; sara.nieto@esa.int).

Y. Kerr and P. Richaume are with Centre d'Etudes Spatiales de la BIOsphère, Toulouse Cedex 31401, France (e-mail: yann.kerr@ cesbio.cnes.fr; philippe.richaume@cesbio.cnes.fr).

S. M. Mecklenburg is with the European Space Agency, European Space Research Institute, Frascati 00044, Italy (e-mail: susanne.mecklenburg@ esa.int).

Color versions of one or more of the figures in this paper are available online at http://ieeexplore.iee.org.

Digital Object Identifier 10.1109/TGRS.2013.2259179 and the Middle East. Detecting and flagging contaminated observations and contacting national authorities to localize and eliminate RFI sources emitting in the protected band present a continuous challenge. This paper describes the regulatory framework for the protection of remote sensors in the 1400-1427-MHz frequency band, the effect RFI has on SMOS data and the different approaches considered to improve the detection, cancellation, and mitigation of the RFI contamination [2]. This paper also provides an overview of how the SMOS RFI scenario has evolved, worldwide and in particular over Europe, following the actions of National Spectrum Management Authorities and the cancellation of many of the RFI sources detected.

\section{International Regulation FOR the PROTECTION} OF THE 1400-1427-MHz PASSIVE BAND

The Earth Exploration Satellite Service (EESS) for passive sensing has a primary frequency allocation in the $1400-1427 \mathrm{MHz}$ band and all emissions are prohibited in this band according to the ITU-R Radio Regulations (RR) footnote 5.340. In addition, the World Radiocommunication Conference 2007 (WRC-07) adopted Resolution 750 on the compatibility between the EESS-passive and relevant active services. As concerns the $1400-1427-\mathrm{MHz}$ band, Resolution 750 contains recommended levels of unwanted emissions applicable to the whole range of ITU-R services allocated in the adjacent bands (Fig. 1) and resolves to urge administrations to take all reasonable steps to ensure that unwanted emissions of active services do not exceed the specific recommended maximum levels, noting that EESS passive sensors provide worldwide measurements that benefit all countries.

The evidence of RFI at levels that prevent geophysical measurements is the rationale for having compulsory (not only recommended) limits to protect the purely passive bands. In Europe, the CEPT Electronic Communications Committee (ECC) approved in March 2011 a new decision $\mathrm{ECC} / \mathrm{DEC} /(11) 01$ on the protection of the EESS (passive) service in the $1400-1427-\mathrm{MHz}$ band. This ECC decision, which was proposed with the support of ESA, CNES, ANFR, and EUMETNET, translates the compatibility criteria recommended by ITU into mandatory limits and intends to give a clear signal to the international community about the recognition by CEPT of the societal and economical values 


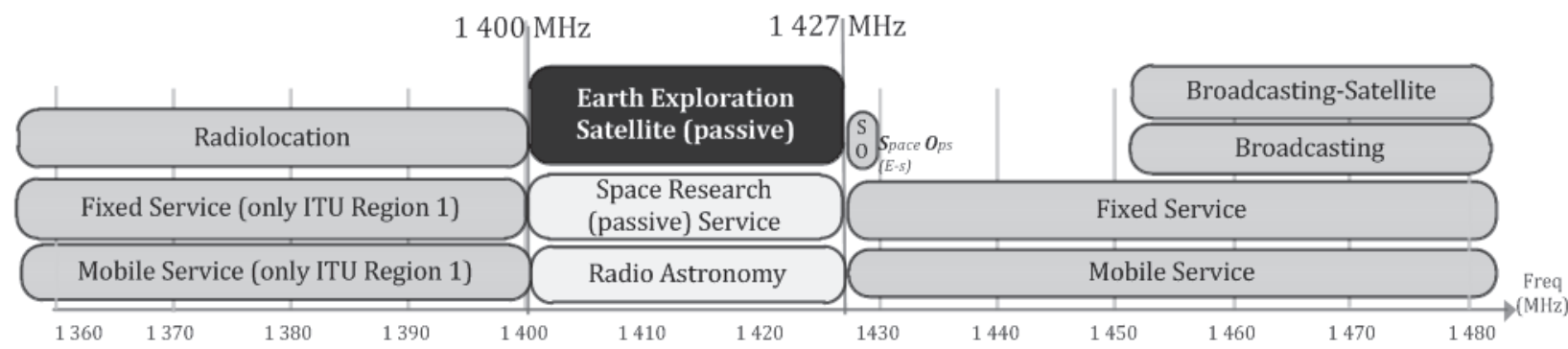

Fig. 1. ITU-R frequency allocations in the 1400-1427-MHz range and adjacent frequency bands [3].

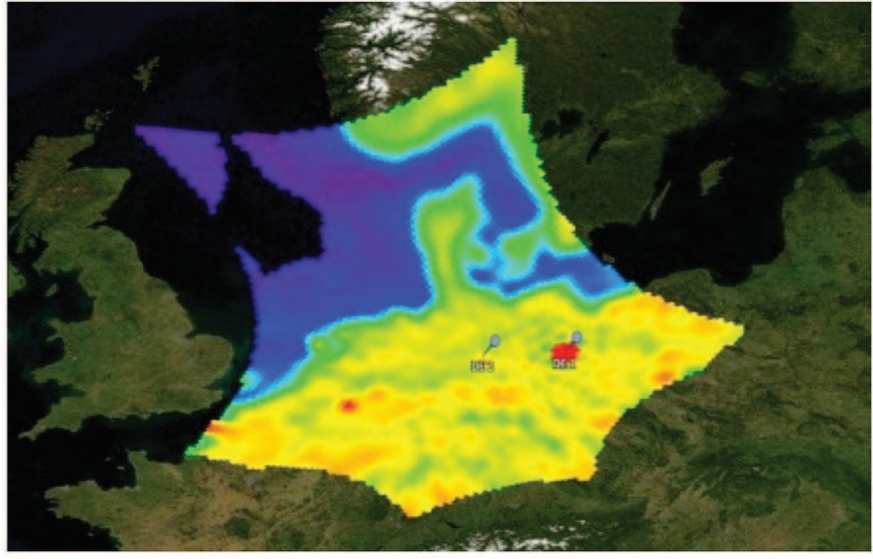

Brightness Temperature $[\mathrm{K}]$

$0.0 \quad 50.0100 .0150 .0200 .0250 .0300 .0350 .0$

Fig. 2. SMOS snapshot showing several RFI emissions detected in Central Europe on October 2010

of the EESS (passive) applications related to climate change and natural disasters prediction. The limits for unwanted emissions apply to stations in the active services operating in CEPT countries in the $1350-1400$ and $1427-1452-\mathrm{MHz}$ bands brought into use after January 1, 2012. Each CEPT administration decides at national level when the ECC decision is implemented. Currently up to ten European countries have already implemented this decision, which is being planned in some others [3]. SMOS, AQUARIUS and in particular future Earth Observation (EO) missions operating in the 1400-1427-MHz passive band, will benefit from this decision.

To increase the awareness of the impact of RFI in the passive sensors, the SMOS RFI issue was brought to the attention of the European Commission, who underlined the importance of strengthening the co-operation of all EU member states in the investigation of the RFI sources over their territories and of taking action to remove, as much as possible, the remaining interferences still being observed [4].

In addition, the Committee on Space Research (COSPAR) also recognized the importance of complying with the regulatory framework and requested all COSPAR national representatives to contact responsible agencies within their countries to take measures to eliminate unauthorized contaminating sources relating to the SMOS mission. Furthermore, ESA has reported the RFI problem faced by SMOS mission in several
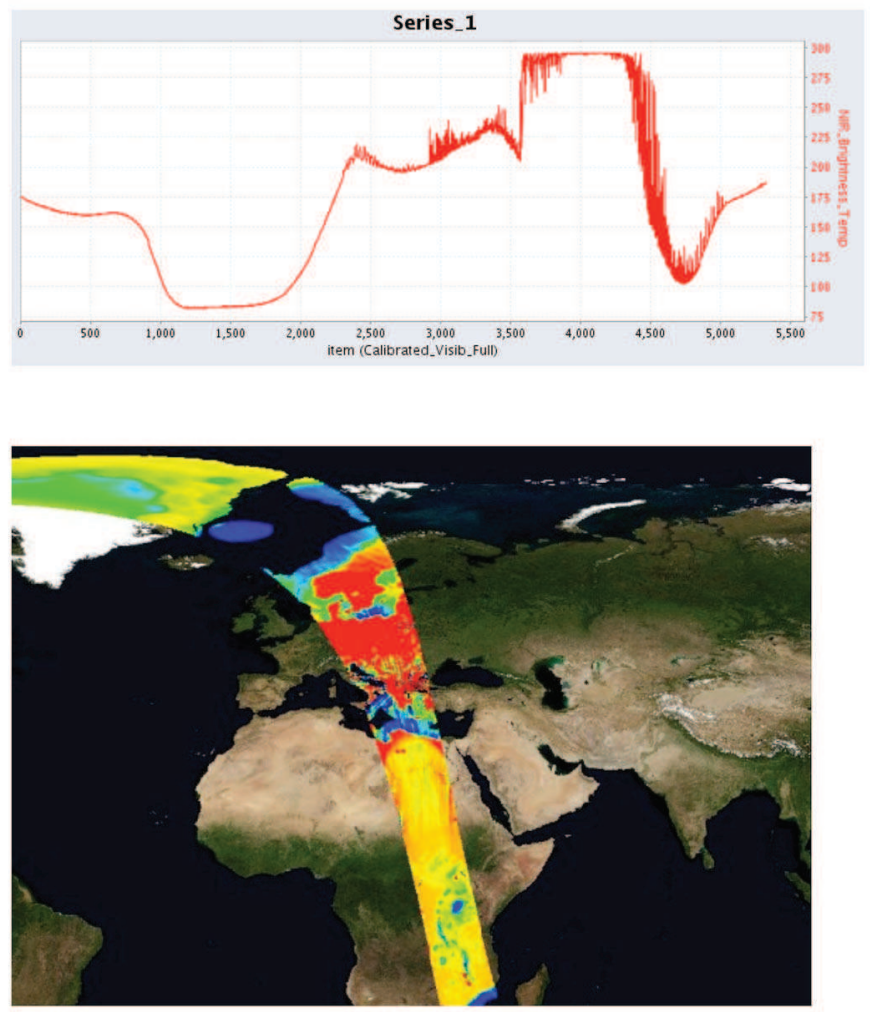

Fig. 3. Impact of very strong RFI emissions, observed as flares in Europe on April 2012 (bottom) and a plot showing the BT level of SMOS reference radiometer, indicating saturation of these receivers (top).

international forums such as the International Telecommunications Union (ITU), the Space Frequency Co-ordination Group (SFCG), the CEPT Frequency Management Working Group, and various scientific conferences (e.g., OCOSS, IGARSS, and EGU).

\section{SMOS RFI OBSERVATIONS}

\section{A. Type of RFI Emissions}

Man-made emissions within the passive band are observed by SMOS as strong point source emissions. The RFI is observed as a brightness temperature (BT) intensity that exceeds the emission radiated by natural sources. The maximum BT because of natural sources is the physical temperature of the source and the maximum ground temperature ever recorded so far is $\sim 338 \mathrm{~K}\left(65{ }^{\circ} \mathrm{C}\right)$. Therefore, BTs values $>340 \mathrm{~K}$ indicate that there is a man-made transmitter in the 


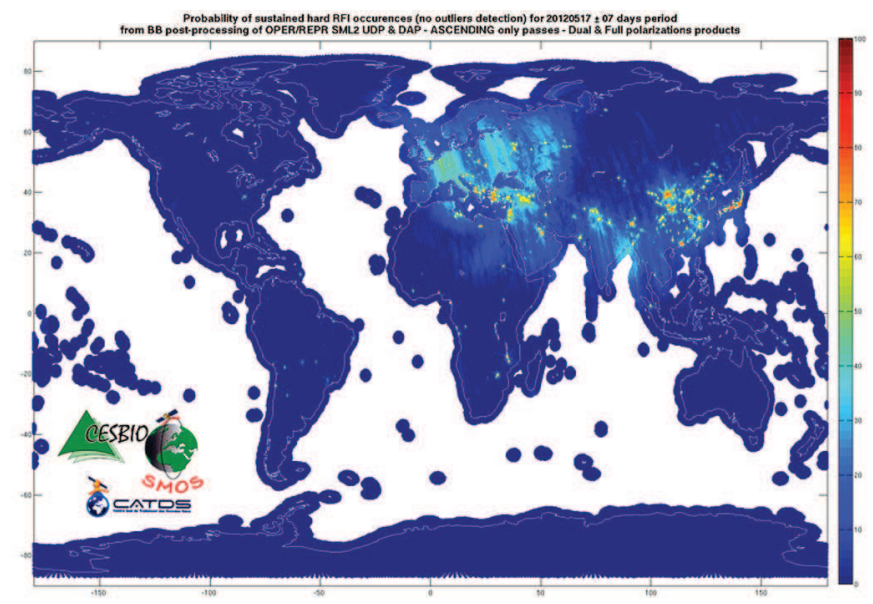

Fig. 4. Worldwide RFI contamination probability during the period of May $10-24,2012$.
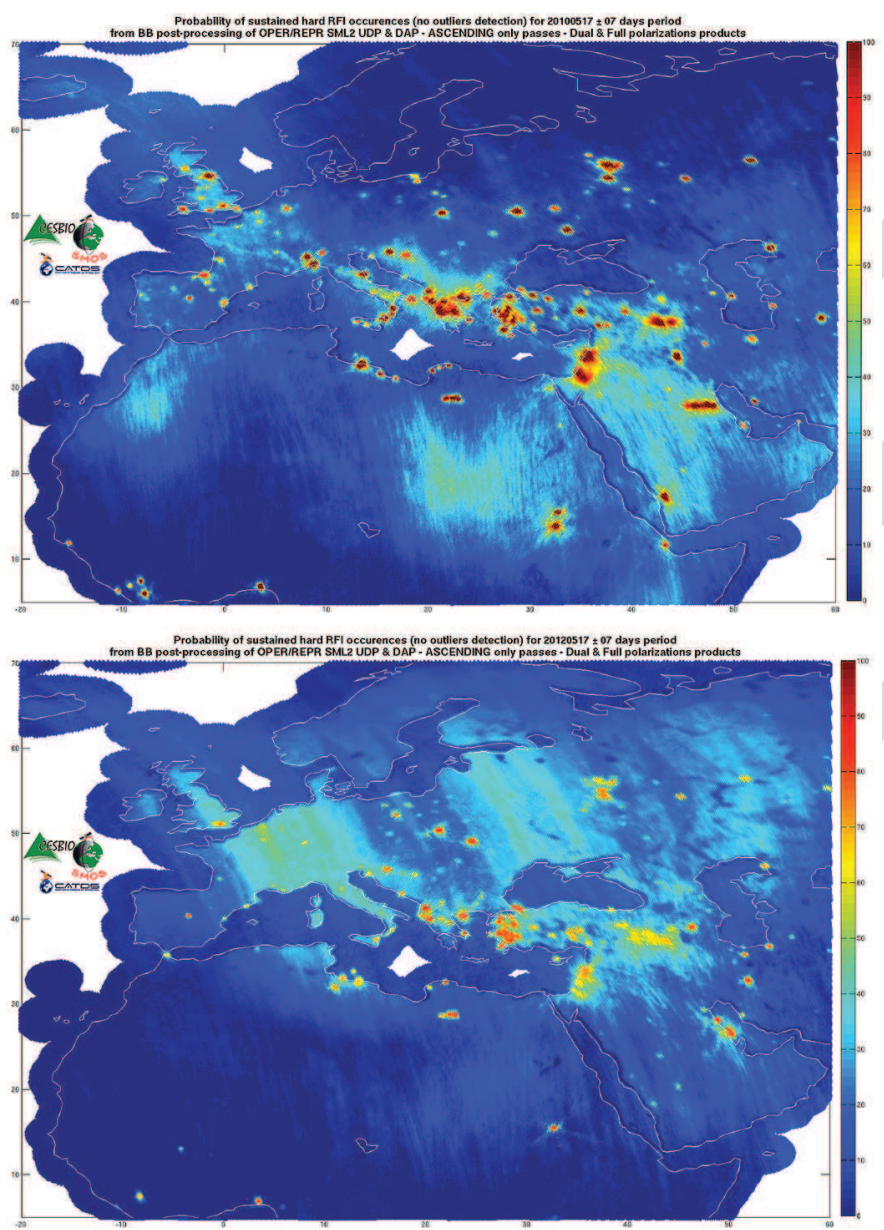

Fig. 5. Probability of sustained RFI occurrence over Europe during 2-weeks time-window (10-24 May) in 2010 (top) and 2012 (bottom).

band without any doubt. RFI emissions can be categorized as low, moderate, strong or very strong as follows.

1) Low RFI emissions have levels similar to natural sources and are difficult to detect, leading to incorrect physical retrieval.

2) Moderate RFI emissions are easily detectable but their effects are circumscribed to the on-ground emitter's
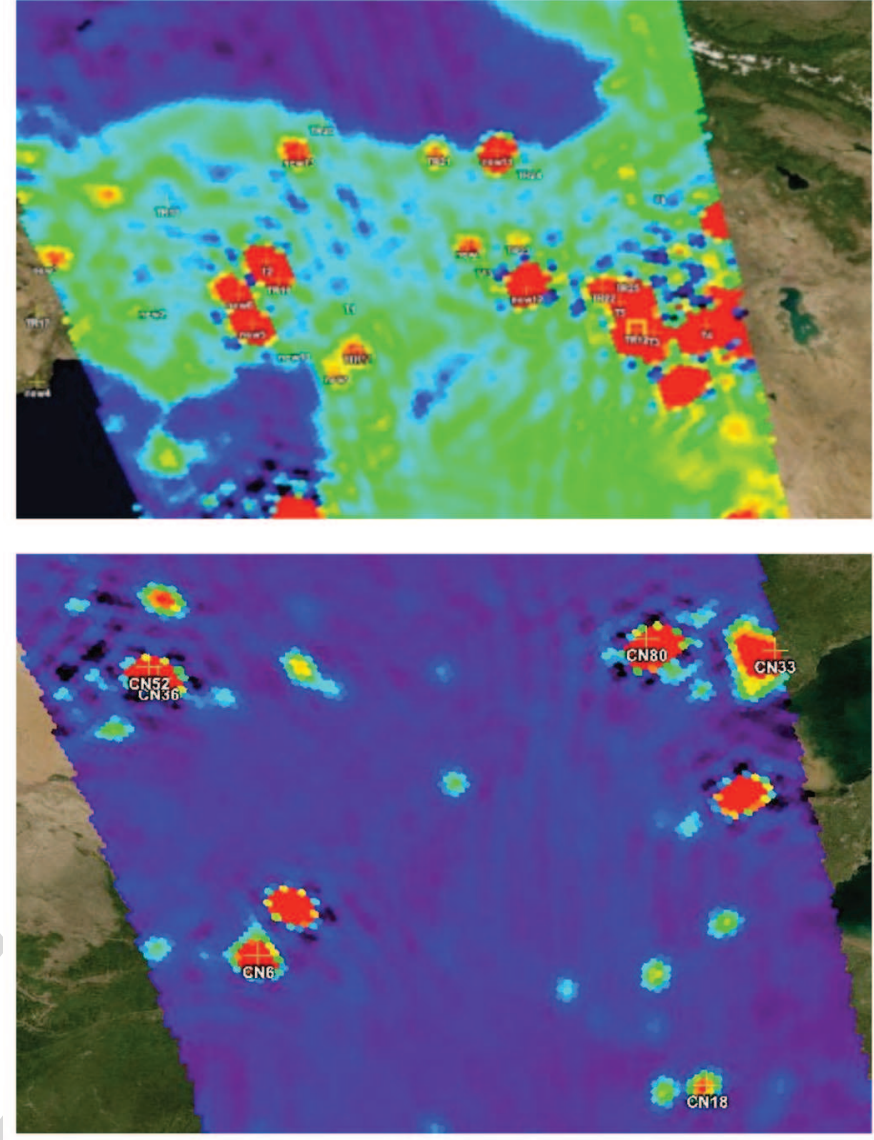

Fig. 6. SMOS images showing geolocation of RFI sources in the area of Turkey/Middle East on November 2011 (top) and over China on January 2012 (bottom).

location. The quality of the data will be negatively affected, with less data available for the retrieval leading to less accuracy (Fig. 2).

3) Strong RFI emissions influence larger areas through the secondary lobes tails, which need to be discarded for scientific retrieval, thus leading to a significant data loss.

4) Very strong RFI emissions essentially hide the full SMOS field-of-view and can blank out any natural signal over a range of several hundreds of kilometers, causing significant loss of data for scientific retrievals. In this respect, there are observed occasional but recurrent RFI flares in Europe that are able to saturate some of SMOS receivers as shown in Fig. 3 .

The RFI sources observed by SMOS can be grouped into two main categories:

1) Illegal in-band emissions in the protected band. These are caused by unauthorized radiolinks, TV and FM broadcast stations, wireless monitoring cameras, malfunctioning DECT phone terminals, and more.

2) Excessive unwanted emissions from systems operating in the adjacent bands. These cause RFI because of outof-band and spurious emissions from radars and other transmitter systems.

The type of emission causing the interference cannot be confirmed based on the SMOS data alone. The feedback 


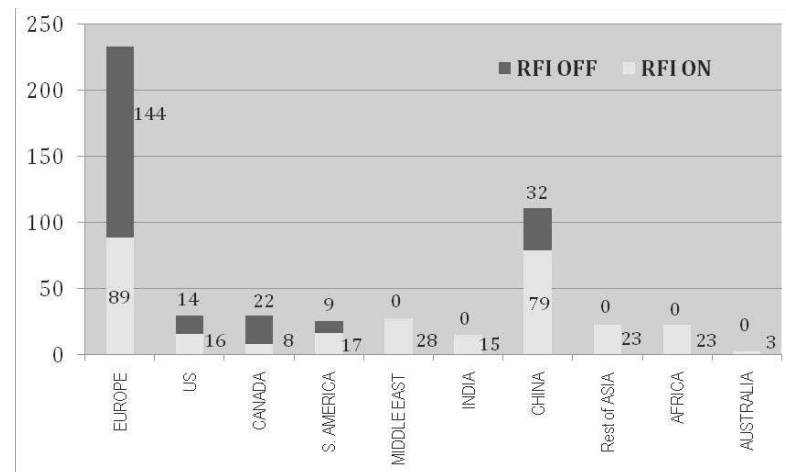

Fig. 7. Overview of SMOS RFI status OFF/ON in September 2012.

\section{SMOS RFI Active: Worldwide Status by September 2012}

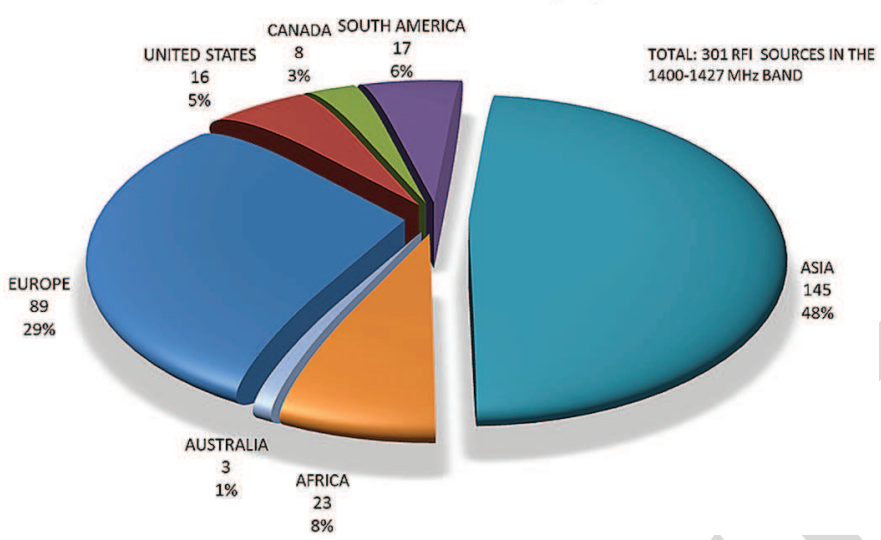

Fig. 8. Distribution of active RFI sources worldwide as of September 2012.

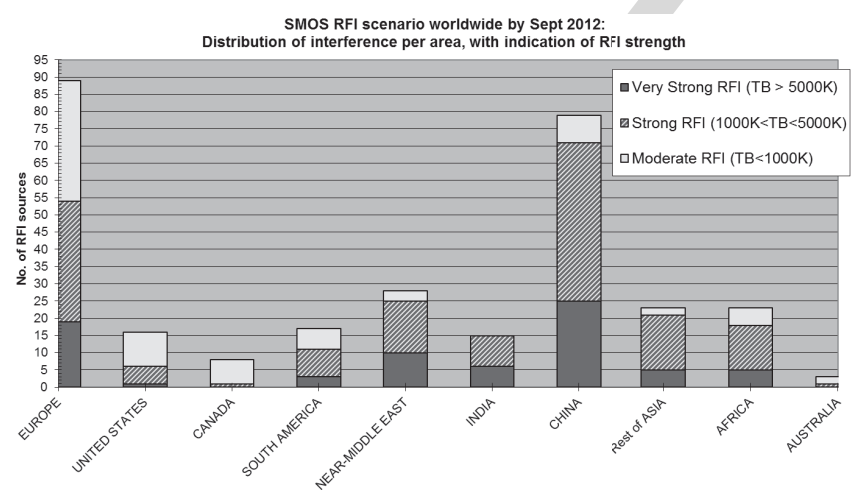

Fig. 9. Distribution of active RFI sources worldwide as of September 2012, classed into moderate, strong, and very strong emission levels.

received from the national spectrum management authorities is key to be able to better characterize the RFI sources and to further improve the interference detection, mitigation, and cancellation techniques.

\section{B. RFI Occurrence Probability Maps}

The Level-2 soil moisture processor allows retrieving statistical information of the SMOS pixels affected by RFI and this data can be presented as probability maps of RFI occurrences during a certain period of time.

The RFI detection included in soil moisture retrieval algorithms allows detecting strong emitters but also weaker

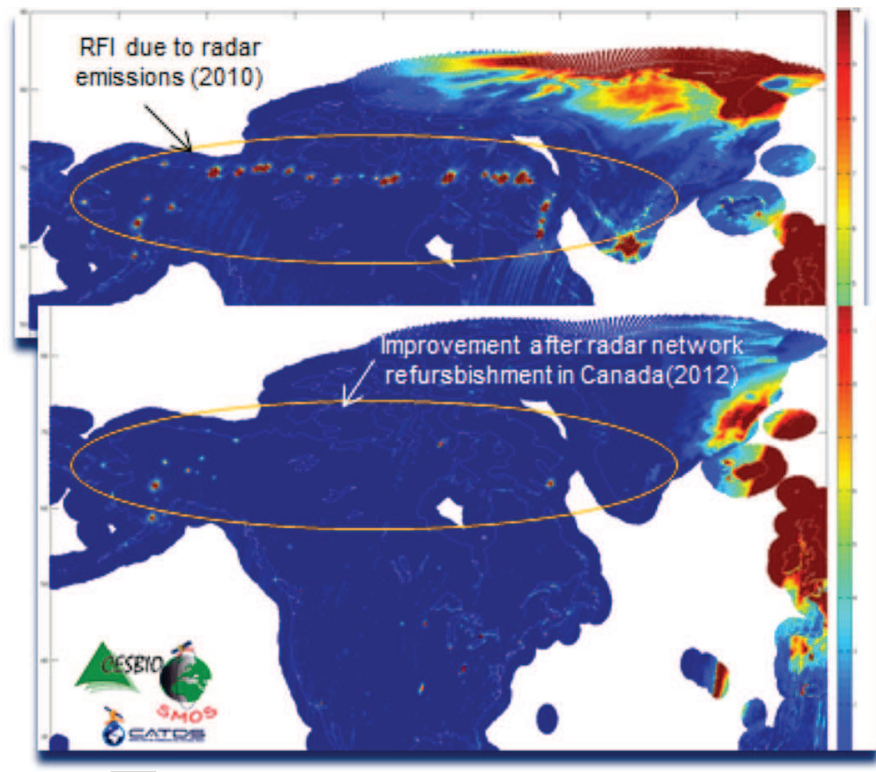

Fig. 10. RFI probability map over North America, showing improvement because of on-going action to refurbish L-Band radar stations in Canada.
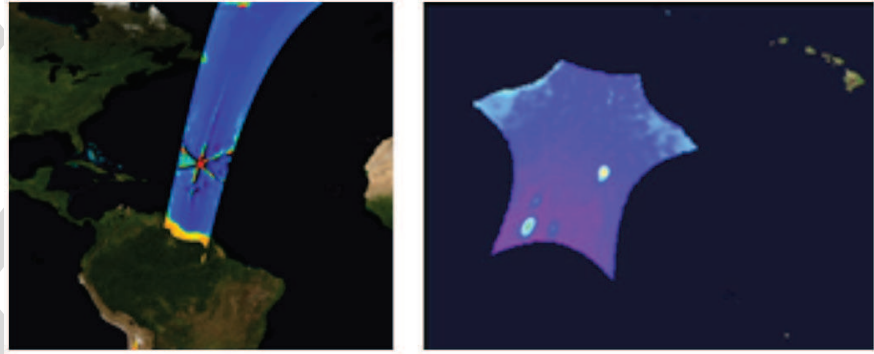

Fig. 11. Cases of RFI observed over the sea in the Caribe in 2010 (left) and near Hawaii in 2012 (right).

sources. As explained, strong sources are detected when their BTs are outside of the geophysical expectation range. This range uses variable thresholds dependent of the minimum/maximum physical earth surface temperature within the antenna footprints. This procedure is stricter than the traditional "maximum maximorum" $340 \mathrm{~K}$ fixed threshold and allows detecting lower BTs values as RFI sources if they are not geophysically plausible given the earth surface estimates (from ECMWF) and considering margins to avoid false alarms. Weaker RFI contaminations are detected through anomalous angular signature on the first Stokes parameter $\left(B T_{\mathrm{X}}+B T_{\mathrm{Y}}\right)$, which is expected not to change much with the incidence angle. Finally, when the soil moisture retrieval is attempted, the farthest outliers with respect to the model solution are eliminated as (possible) soft RFI sources (larger than four times the BTs radiometric uncertainties).

The basis of probability maps is to count the number of BTs considered as contaminated per pixel and orbit and to accumulate counters as the beginning of the mission in daily global files maps. These files are called as DGG current RFI and hold the three counters: $\mathrm{NRFI}_{\mathrm{X}}$, NRFI $\mathrm{N}_{\mathrm{Y}}$, and NSNAP. NRFI $_{X}$ (resp. NRFIY) are the number of BTs detected as contaminated on X (resp. Y) antenna polarization, whereas 


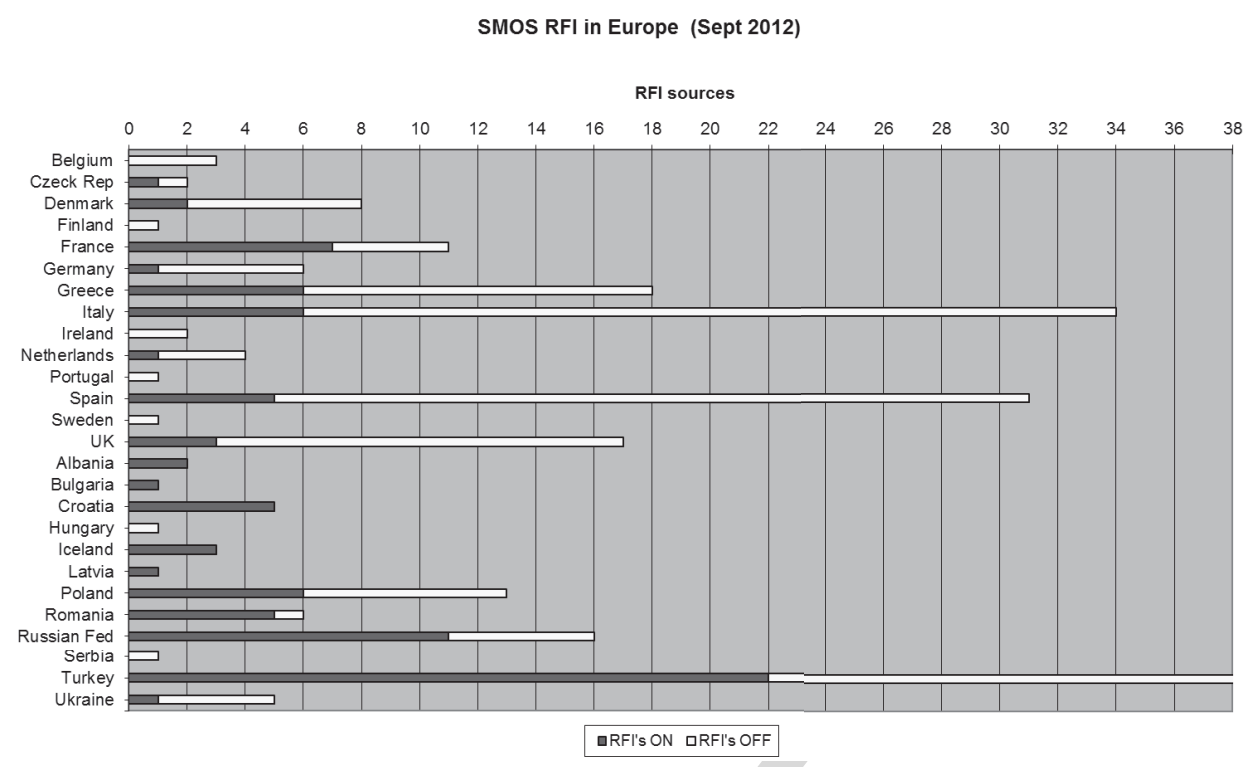

Fig. 12. Distribution active and switched off RFI sources over Europe by country (status September 2012).

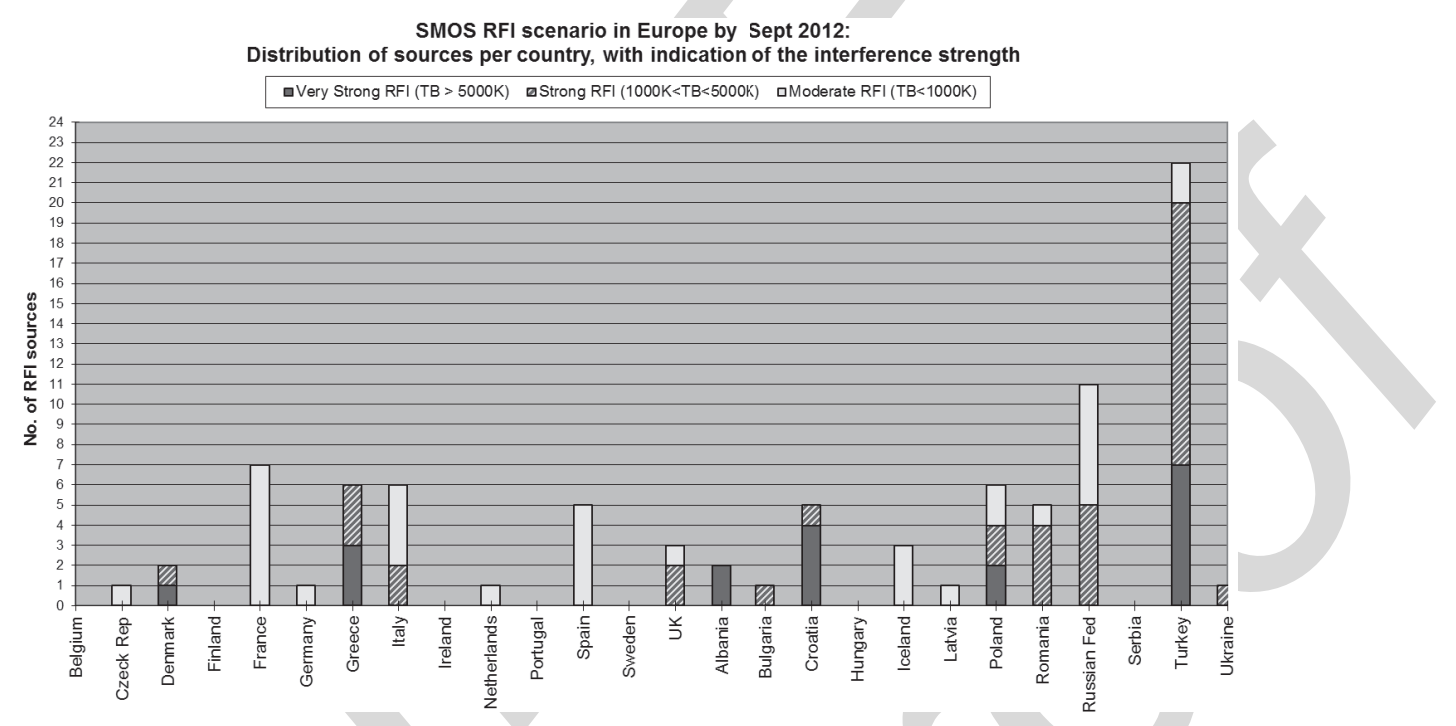

Fig. 13. Distribution of active RFI sources over Europe as of September 2012, classed into moderate, strong, and very strong emission levels.

NSNAP is the total number of observed BTs. Then, $P=$ $\left(\mathrm{NRFI}_{\mathrm{X}}+\mathrm{NRFI}_{\mathrm{Y}}\right) / \mathrm{NSNAP}$ defines a probability of RFI occurrences as the beginning of the mission up to the validity date of a given DGG current RFI map. By differentiating two DGG current RFI counters maps for two dates, the probability of RFI occurrences can be computed for the specific time period that these two dates define. This is shown in the three following probability maps for 15 days time window at various dates.

The worldwide RFI probability map during the period May 10-24, 2012 is shown in Fig. 4, and the detailed maps over Europe for 2010 and 2012 are shown in Fig. 5. The color bar ranges from red (100\%), indicating that RFIs are always present and means that no BT measurements were kept at all during 15 days, to deep blue, indicating none to very low probability and thus almost all BT measurements were kept as usable for retrieval. Intermediate values indicate a high proportion of RFI presence but do not tell when the occurrences appeared within the time window considered. For the 15 days time window illustrated in these maps, a probability of $50 \%$ (green) is equally obtained by 7.5 days of continuous strong emissions followed by 7.5 days of no emission at all or by alternating one day with strong RFI followed by one day RFI off or any other combinations.

These maps do not include outliers to models but only the radiometric detection to avoid any controversy about the validity of models that may create false alarms. In the same spirit, reasonable margins in thresholds and the use of the radiometric uncertainty are taken into consideration for the detection to avoid false alarms. The presented maps, though scary as they are, must be considered optimistic; the reality is certainly worse because of the margins taken, of the fact that the stronger RFI sources may be masking weaker RFI emitters 


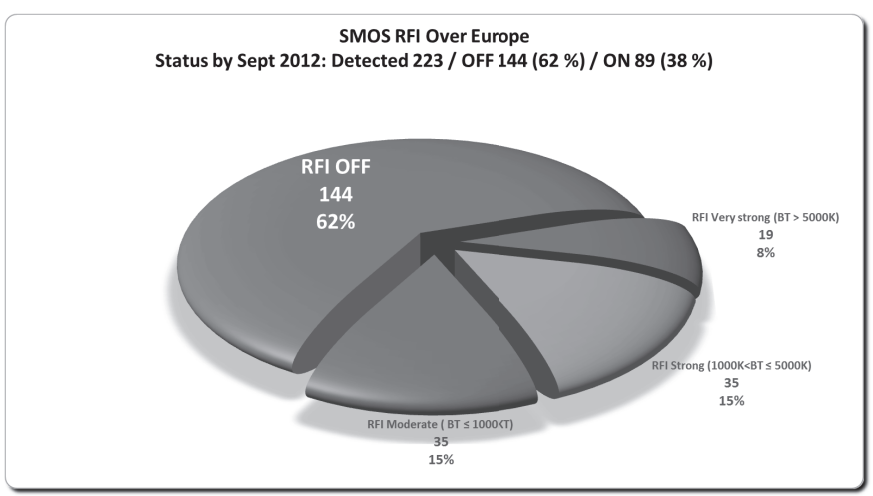

Fig. 14. Global statistics of SMOS RFI over Europe. Status of September 2012.

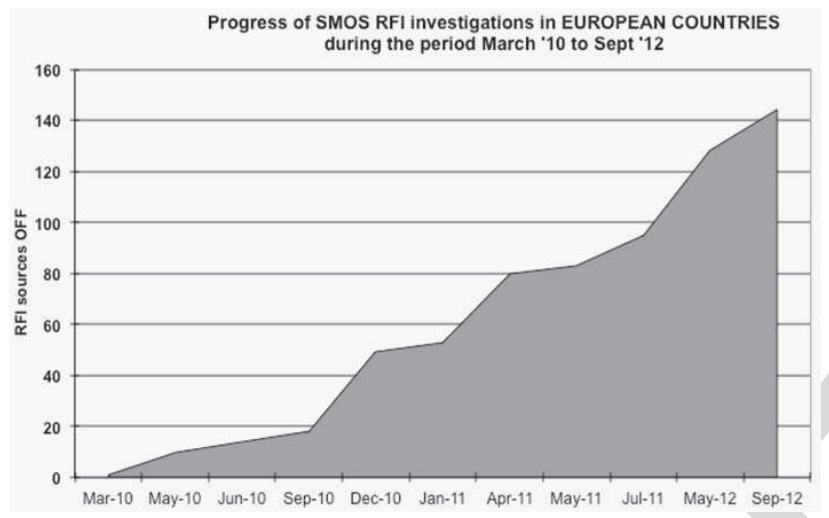

Fig. 15. Evolution of SMOS RFI investigations over Europe in co-operation with the National Spectrum Management Authorities as of September 2012.

and of the difficulty in detecting RFI emissions of moderate strength very close to BT values from natural sources.

\section{RFI Detection and Geolocation Process}

SMOS L1c products provide geolocated measurements of BT. These measurements integrate the radiation received at the satellite every $1.2 \mathrm{~s}$.

A team of data analysts regularly scans these SMOS images and the probability maps presented in the previous section for new RFI sources. Whenever a RFI is detected, a semiautomatic algorithm [5] analyzes several SMOS passes over that area. The objective of the algorithm is to estimate, as best as possible, the on-ground location of the RFI and its BT intensity (see Fig. 6). This information is then transmitted to the national spectrum management authorities of the country. These will initiate investigations about the location and origin of the RFI source and will take the necessary actions to either switch off the emitter or repair malfunctioning equipment until the interference is eliminated.

Even though SMOS spatial resolution $(35-55 \mathrm{~km})$ is not very adequate for this purpose, the algorithm relies on the large amount of observations to improve the accuracy of the geographical co-ordinates of the antenna emitter. Considering that during one pass, each point on-ground is measured several times under different incidence angles (as the satellite moves forward) and that at least two weeks of measurements over that
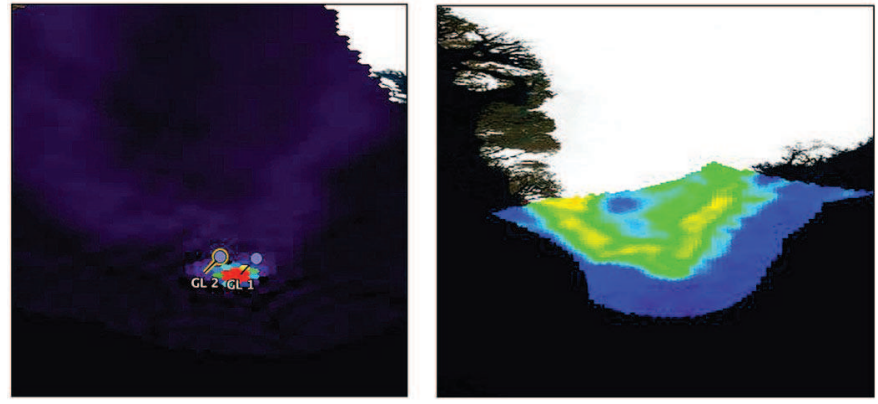

Fig. 16. Evolution of SMOS RFI investigations over Greenland [December 2010 (left) to March 2011 (right)].
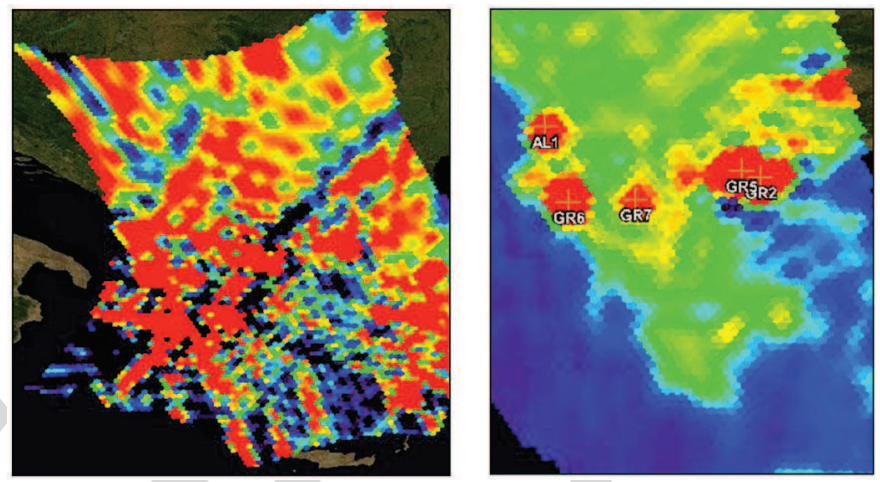

Fig. 17. Evolution of SMOS RFI investigations over Greece [June 2010 (left) to April 2011 (right)].

region (i.e., $\sim 10$ passes) are used to infer the RFI position, the final accuracy of this technique is better than $5 \mathrm{~km}$ in the majority of the cases.

Other characteristics that can be derived in this geolocation process are the RFI emitter pointing direction and periodicity (e.g., pulsed emissions from scanning radars, nonpermanent sources, continuous emissions, and so on).

The BT associated to each RFI only aims to characterize a first-order estimation of the intensity and to prioritize within the RFIs detected in one particular country which ones are most harmful to SMOS measurements. The majority of the RFI sources correspond to terrestrial emitters with low elevation, whereas the satellite measurements correspond to almost zenith observations. Therefore, the BT values measured do not fully represent the total power transmitted by the interference source in the passive band.

A very important aspect of the RFI detection process, together with the accuracy, is reliability. The aim is not to provide any false alarm detection to the spectrum management authorities, which could involve the mobilization of a ground monitoring patrol team looking for an inexistent RFI. This situation would discourage the national authorities' efforts to improve SMOS RFI situation over their territories.

\section{APPROACHES to IMPROVE SMOS RFI SituATION}

\section{A. General Description of the Approaches Considered}

Several strategies are put in place to improve scientific retrieval of SMOS team under the RFI scenario observed worldwide as follows: 

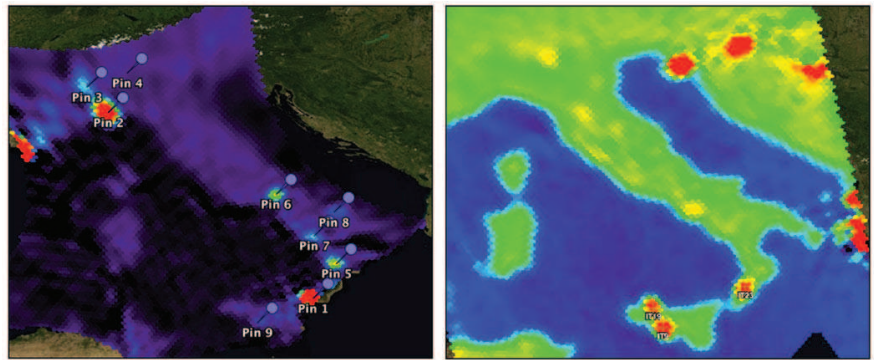

Fig. 18. Evolution of SMOS RFI investigations over Italy [July 2010 (left) to April 2011 (right)].
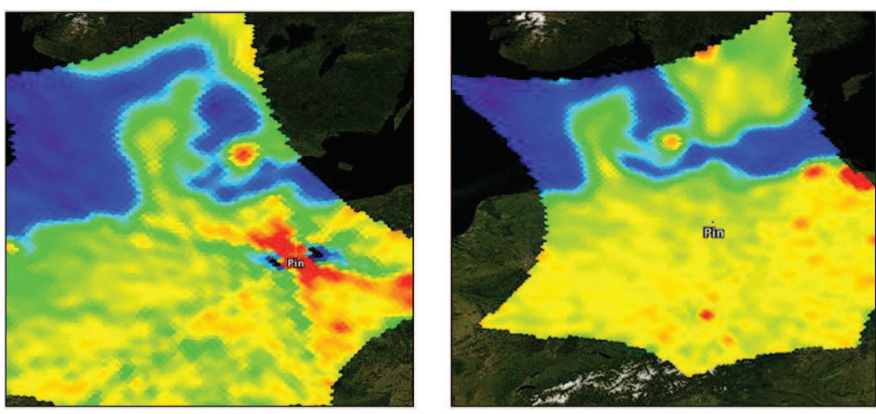

Fig. 19. Evolution of SMOS RFI investigations over Germany [January 2011 (left) to February 2011 (right)].

1) In the short and medium term:

a) to report the detected RFI sources to the National Spectrum Management Authorities and request for their support to initiate investigations. Main outcome of this initiative is the cancellation of those RFI sources because of emitters that do not comply with ITU regulations;

b) to localize and flag the RFI contamination in the respective Level-1 data product, thus avoiding that this data is used for the retrieval of Level-2 data products. Flagging techniques have associated an important loss of data although they increase the reliability in the scientific retrieved data;

c) to investigate new RFI mitigation algorithms. New approaches to mitigate or cancel the RFI impact are under development and preliminary testing is being conducted. Interference mitigation techniques have either big uncertainties associated to their corrections or imply a degradation of certain instrument characteristics, such as spatial resolution, in favour, for example, of a reduction of the synthetic beam secondary side-lobes. Therefore, the real benefit of such techniques is still to be proved.

2) In the medium and long term:

a) to increase the awareness of the international telecom community about the ITU radio-regulations, both in terms of prohibiting any emissions in the passive band, and also in terms of respecting the maximum levels recommended for unwanted emissions (in the passive band) because of active services in adjacent bands. It is important to remember that the removal of strong RFI sources does not mean that the band is entirely free
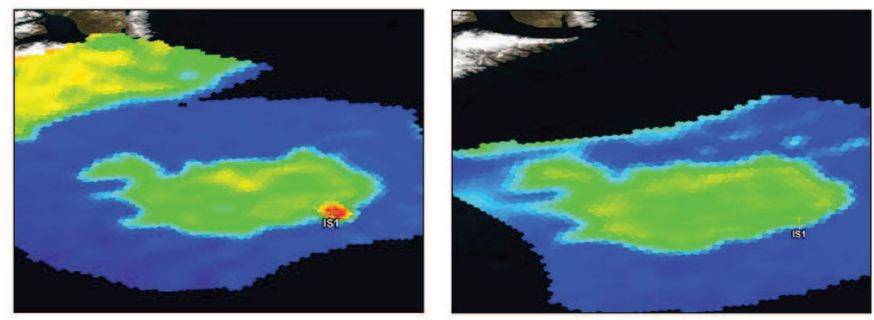

Fig. 20. Evolution of SMOS RFI investigations over Iceland [March 2011 (left) to April 2011 (right)].
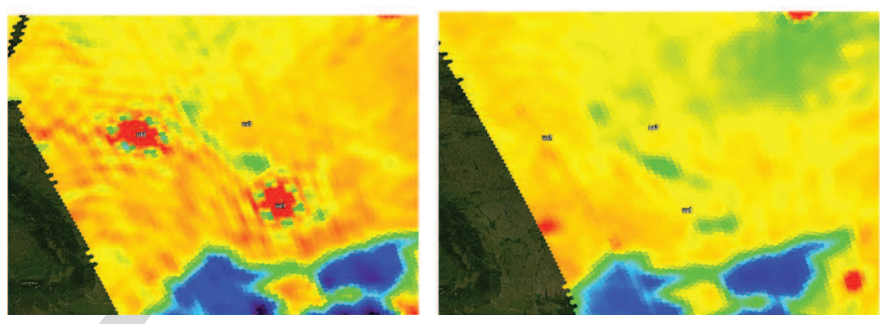

Fig. 21. Evolution of SMOS RFI investigations over Ukraine [December 2010 (left) to August 2011 (right)].

of interference, as low level RFI can still be present and create erroneous data.

\section{B. Worldwide Evolution of SMOS RFI}

ESA regularly reports the interference cases to the spectrum management authorities of the different countries so that they can initiate investigations, identify the type of emitter and take appropriate actions.

Following a careful analysis of the retrieved data, ESA prepares a RFI catalog/country, containing detailed information of the geolocation, BT measurements, and characteristics of the RFI source for all interferences detected over the territory. This information is typically provided together with a snapshot of SMOS observations over the area of interest. The spectrum management authorities normally distribute the information on RFI sources/regions, and then delegate regional office the task of investigation and on-site monitoring of the reported RFI locations.

An overall SMOS RFI catalog is updated regularly and allows ESA to keep track of the process in the identification and switching off of RFI sources. The investigation of RFIs is often an iterative process that requires the co-operation of the authorities and the co-ordination and regular RFI status updates provided by SMOS RFI team. This procedure is timeconsuming and not always successful, but has proven to be effective to improve the interference scenario over extensive areas.

So far ESA has contacted 45 administrations and reported $>500$ RFI sources, most of them located in Europe and Asia. Approximately $42 \%$ of the RFI sources were successfully identified and switched off. Fig. 7 shows an overview of the worldwide progress in the investigations since early 2010 until now. A significant improvement is observed in Europe (144 RFI off), Canada (22 RFI off), and the United States of America (14 RFI off). Since early 2012 some improvement 

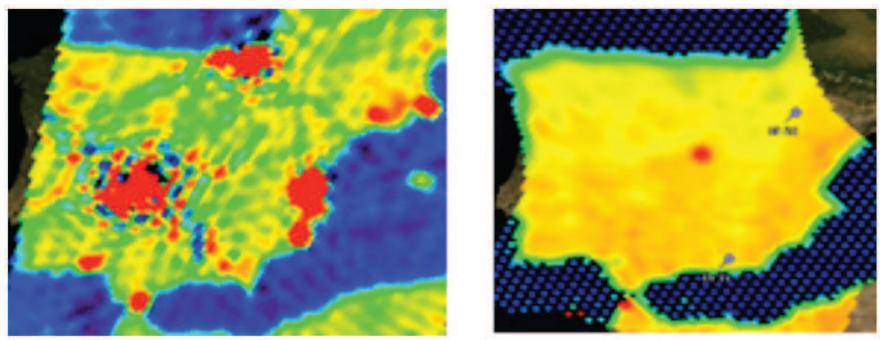

Fig. 22. Evolution of SMOS RFI investigations over Spain [January 2010 (left) to June 2012 (right)].

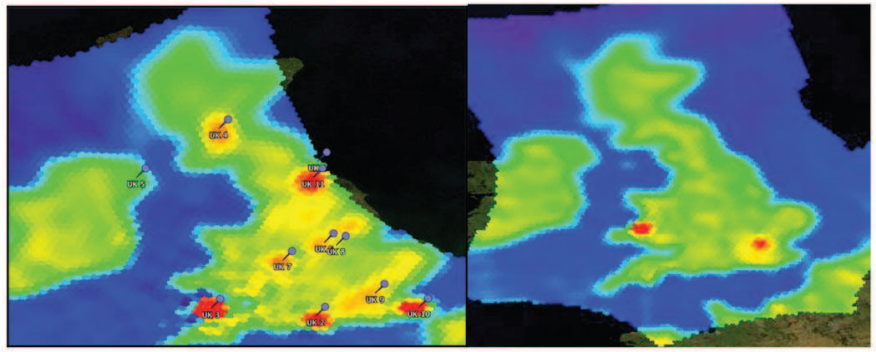

Fig. 23. Evolution of SMOS RFI investigations over United Kingdom [June 2010 (left) to January 2012 (right)].

is also observed in Asia, with 32 RFI sources switched off in China, although the continent still remain much polluted by RFI and with the strongest emitters in the passive band. By September 2012, there are up to 300 RFIs still active worldwide and the more polluted areas are Middle East, China, and some areas in Europe. See the distribution worldwide of the active RFI sources in Figs. 8 and 9.

The out-of-band emissions from radar systems are confirmed as RFI sources in numerous cases. The adjustment of some technical parameters or repair of malfunctioning modules has fixed the problem in several occasions. In other cases, the refurbishment of the radar station was necessary to ensure compliance with the unwanted emissions maximum levels set by ITU-R regulations. Because of the commitment of the national authorities the situation concerning radar interferences is improving in several countries, as was the case of Canada, shown in Fig. 10.

Continental regions are not the only ones affected by RFI. Fig. 11 shows two cases of RFI emitted from boats observed near the Caribbean islands (2010) and more recently in the Pacific Ocean, near Hawaii (2012).

\section{Evolution of SMOS RFI in Europe}

Since early 2010, > 220 RFI were detected over Europe and 144 RFIs were successfully switched off because of the cooperation of the National Spectrum Management Authorities. Fig. 12 shows an overview of the number of RFI sources on/off/country, and Fig. 13 shows the distribution/country in terms of BT intensity (moderate, strong, and very strong) for those sources active in September 2012. Finally, Fig. 14 shows the global statistics as of Europe.

The authorities of up to 26 European countries are cooperating with ESA in the investigation of the RFI over their territories. The evolution and the results obtained from their involvement are shown in Fig. 15.

A significant improvement is observed since SMOS launch and this is noticeable when comparing the satellite snapshots before and after actions were taken to cancel the RFI. See for example the cases of Greenland (Fig. 16), Greece (Fig. 17), Italy (Fig. 18), Germany (Fig. 19), Iceland (Fig. 20), Ukraine (Fig. 21), Spain (Fig. 22), and United Kingdom (Fig. 23).

\section{Conclusion}

This paper showed that it is essential to protect the passive band 1400-1427 MHz from both illegal in-band emissions and excessive unwanted emissions. While the solution of the RFI because of illegal emissions can be achieved with the co-operation of the national authorities, the solution of the excessive unwanted emissions problem would also require regulatory action and compliance with the levels adopted in ITU-R Resolution 750 (WRC-07). This effort had to be continued and intensified by raising concern among the different countries and organizations about the impact of RFI on scientific observations in particular from potential new services or systems that could be authorized in the adjacent bands.

\section{ACKNOWLEDGMENT}

The authors would like to thank various scientific and industrial teams working together to alleviate the RFI situation (ACRI, CESBIO, DEIMOS, DTU, ESA, IFREMER, INSA, IRAP, and UPC), and also would like to thank their valuable contributions and continuous encouragement to improve the RFI environment received from SMOS Team, in particular M. M. Neira, SMOS Principal Payload Engineer and E. Marelli, ESA Frequency Manager. For the continuous work and support for the protection of the EESS passive bands J. Pla from CNES and P. Tristant from EUMETNET are also appreciated. The support and involvement in the investigation of RFI sources of all National Frequency Regulation Authorities is a key factor to ensure the improvement of SMOS RFI scenario, and ESA is very thankful to all Administrations for this support. In particular, the authors would like to recognize the excellent results achieved in Spain thanks to the co-operation of J. C. Vallejo, from the Dirección General de Telecomunicaciones (Spain). For their contribution to improve the RFI situation over their countries, the authors would like to also recognize the following persons and institutions: G. Ducheyne and $\mathrm{F}$. Vindevoghel of the Belgisch Instituut voor postdiensten and telecommunicatie and R. De Wiest of the Section Radar at ATCC Belgium Air component (Belgium); H. Blume, of the Danish National IT and Telecom Agency (Denmark); J. Kallio of the Finnish Communications Regulatory Authority and J. Kainulainen at Aalto University (Finland); J. Guyomard from ANFR (France); J. Nitschke of BNetZA and U. Birkenstok of the German Air Force Command (Germany); C. Kechribaris of the Spectrum Monitoring Department EETT (Greece); D. Spoto of the Ministero dello Sviluppo Economico and F. Biondi of the Defense Ministry (Italy); V. Ernir Axelsson of the Icelandic Coast Guard and T. Jónasson of the Post and Telecom Administration of Iceland; M. van Rouwendal 
of the Ministerie van Defensie and L. Ket of the Dutch radiocommunications agency (The Netherlands); B. Dudhia of OfCom (UK); I. Gepko of the Ukrainian State Center of Radio Frequencies (UCRF), Zeng and Zhao (SRRC China), J. Andrzejczak of the Department of Spectrum Control at UKE (Poland), E. Cherian of Federal Comms Commission (United States); and Ly Bun-Ret and A. Ongaro, of the Spectrum, Information Technologies, and Telecommunications Sector (Canada).

\section{REFERENCES}

[1] S. Mecklenburg, M. Drusch, Y. Kerr, J. Font, M. Martin-Neira, S. Delwart, G. Buenadicha, N. Reul, E. Daganzo-Eusebio, R. Oliva, and R. Crapolicchio, "ESA's Soil Moisture and Ocean Salinity mission: An overview after one year of operations," IEEE Trans. Geosci. Remote Sens., vol. 50, no. 5, pp. 1345-1356, May 2012.

[2] R. Oliva, E. Daganzo-Eusebio, Y. H. Kerr, S. Mecklenburg, S. Nieto P. Richaume, and C. Gruhier, "SMOS radio frequency interference scenario: Status and actions taken to improve the RFI environment in the 1400-1427-MHz passive band," IEEE Trans. Geosci. Remote Sens., vol. 50, no. 5, pp. 1427-1439, May 2012.

[3] (2011). Implementation Status for Decision ECC/DEC/(11)01 [Online]. Available: http://www.erodocdb.dk/doks/implement_doc_ adm.aspx?docid $=2398$

[4] European Commission Radio Spectrum Committee. (2010). Update from France on the Interference to SMOS Satellite Operating Within the EESS (Passive) Frequency Band 1400-1427 MHz [Online]. Available: http://ec.europa.eu/information_society/policy/ecomm/radio_spectrum/_ document_storage/rsc/rsc34_public_docs/rscom10_70.pdf

[5] R. Oliva, S. Nieto, and F. Felix, "RFI detection algorithm: Accurate geolocation of the interfering sources in SMOS images," IEEE Trans. Geosci. Remote Sens., 2013, to be published.

Elena Daganzo-Eusebio received the M.Sc. degree in telecommunication engineering from the Polytechnic University of Madrid, Madrid, Spain.

She joined the European Space Agency (ESA), Operations Center, Darmstadt, Germany, in 1992, as a Ground Segment Systems Engineer and participated in the preparation of the ESA ground network to support LEOP and mission operations. Since 1996, she has worked in several areas with the European Space Research and Technology Centre, first as TT\&C and RF System Engineer with the Technical Directorate and since 2009 in Frequency Management Engineer in the Directorate of Earth Observation Programmes. She analyzes the requirements and constraints of EO missions with respect to frequency allocation and interference and monitors the evolution of the frequency needs for future missions. She participates in the work of technical committees in the frame of ITU, CEPT, and SFCG. She is following up the contacts with the National Frequency Management Administrations in order to improve SMOS RF interference environment.

Roger Oliva received the M.S. degree in telecommunication engineering from the Polytechnic University of Catalonia, Catalonia, Spain, and the M.S. degree in astronomy (D.E.A.) degree from Barcelona University, Barcelona, Spain.

He has worked on several space and astronomy projects, including Mars Express, astronomical microwave observatories and in the design of advanced telecommunications satellite payloads. Since 2007, he has been a Calibration Engineer for the European Space Agency, Earth Observation satellite SMOS.
Yann H. Kerr (M'88-SM'01-F'13) received the Engineering degree from Ecole Nationale Supérieure de l'Aéronautique et de l'Espace, the M.Sc. degree in electronics and electrical engineering from Glasgow University, Glasgow, U.K., and the Ph.D. degree from the Astrophysique Gophysique et Techniques Spatiales, Université Paul Sabatier, Toulouse, France.

$\mathrm{He}$ is currently the Director of Centre d'Etudes Spatiales de la BIOsphère, Toulouse. He was an EOS Principal Investigator (interdisciplinary investigations) and PI and precursor of the use of the SCAT over land. In 1990, he started to work on the interferometric concept applied to passive microwave earth observation and was subsequently the science lead on the MIRAS project for ESA. In 1997, he proposed the SMOS Mission, the natural outcome of the previous MIRAS work. He is currently involved in the exploitation of SMOS data, in the Cal Val activities and related level 2 soil moisture and level 3 and 4 developments. He is working on the SMOS next concept and involved in both the Aquarius and SMAP missions. He is a Distinguished Lecturer for GRSS. His current research interests include theory and techniques for microwave and thermal infrared remote sensing of the Earth, with an emphasis on hydrology and water resources management.

Dr. Kerr was a recipient of the World Meteorological Organization 1st Prize (Norbert Gerbier), the USDA Secretary's Team Award for Excellence (Salsa Program), the GRSS certificate of recognition for leadership in development of the first synthetic aperture microwave radiometer in space and success of the SMOS mission.

Sara Nieto received the B.S. degree in computer science, specializing in information systems development and artificial intelligence from the Universidad Carlos III de Madrid, Madrid, Spain.

She has been a part of the SMOS Operations Team, European Space Astronomy Centre, Madrid, since April 2010, where she provides support on radio frequency interference detection.

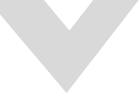

Philippe Richaume received the Engineer degree in computer, electronic, and automatic from Ecole Supérieure d'Informatique, Electronique et Automatique, Paris, France, in 1990, the M.Sc. degree in computer sciences and artificial intelligence from Paul Sabatier University, Toulouse, France, in 1991, and the Ph.D. degree in computer sciences and applied mathematics from CNAM, Paris, 1996.

$\mathrm{He}$ has worked in various geophysical laboratories, putting to test advanced computer science and applied mathematics paradigms against real problems, particularly in the remote sensing context. He is currently with the Centre d'Etudes Spatiales de la BIOsphère, Toulouse, France. His current research interests include nonlinear modeling and inverse problem, particularly using artificial neural networks, such as for a radio receiver real time controller dedicated to solar wind plasma line tracking onboard the WIND/WAVES spacecraft, or for direct-inverse modeling of ocean surface wind from ERS $1 / 2$ scatterometer or biophysical parameters, LAI, chlorophyll, from POLDER optical directional reflectance, or using traditional approaches like for soil moisture retrieval from SMOS brightness temperature.

Susanne Martha Mecklenburg received the M.S. degree in hydrology from the Technical University of Dresden, Dresden, Germany, and the Ph.D. degree in atmospheric science from the Swiss Institute of Technology, Zurich, Switzerland.

She joined the European Space Research Institute, European Space Agency (ESA), Frascati, Italy, in 2007, to take up the position of the SMOS Mission Manager. Before joining ESA, she was with the British National Space Centre, U.K. 